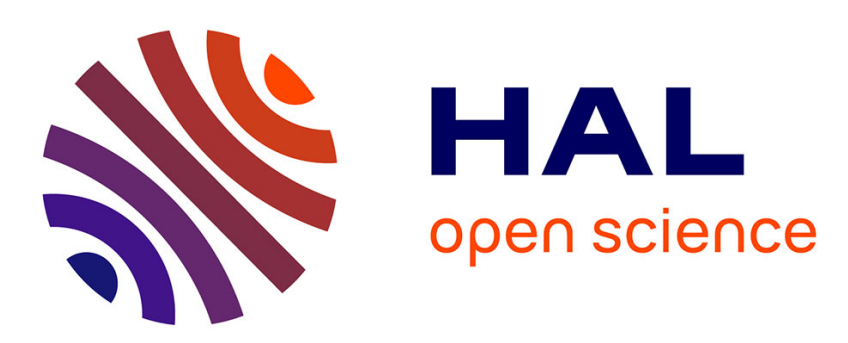

\title{
An evaluation of SCOPE: A tool to simulate the directional anisotropy of satellite-measured surface temperatures
}

C Duffour, A Olioso, J Demarty, C van Der Tol, J.-P Lagouarde

\section{- To cite this version:}

C Duffour, A Olioso, J Demarty, C van Der Tol, J.-P Lagouarde. An evaluation of SCOPE: A tool to simulate the directional anisotropy of satellite-measured surface temperatures. Remote Sensing of Environment, 2014, 158, pp.362-375. 10.1016/j.rse.2014.10.019 . hal-01317518

\author{
HAL Id: hal-01317518 \\ https://hal.science/hal-01317518
}

Submitted on 28 May 2020

HAL is a multi-disciplinary open access archive for the deposit and dissemination of scientific research documents, whether they are published or not. The documents may come from teaching and research institutions in France or abroad, or from public or private research centers.
L'archive ouverte pluridisciplinaire HAL, est destinée au dépôt et à la diffusion de documents scientifiques de niveau recherche, publiés ou non, émanant des établissements d'enseignement et de recherche français ou étrangers, des laboratoires publics ou privés. 


\title{
An evaluation of SCOPE: A tool to simulate the directional anisotropy of satellite-measured surface temperatures
}

\author{
C. Duffour ${ }^{\mathrm{a}, 1}$, A. Olioso ${ }^{\mathrm{b}, \mathrm{c}}$, J. Demarty $^{\mathrm{d}}, \mathrm{C}$. Van der Tol ${ }^{\mathrm{e}}$, J.-P. Lagouarde ${ }^{\mathrm{a}}$ \\ a INRA, UMR 1391 ISPA, F-33140 Villenave d'Ornon, France \\ b INRA, UMR1114 EMMAH, F-84 914 Avignon, France \\ c INRA, UMR 1114 UAPV, F-84 914 Avignon, France \\ d UMR HydroSciences Montpellier, UMR5569 CNRS/IRD/UM1/UM2, F-34095 Montpellier, France \\ e Faculty of Geo-Information Science and Earth Observation (ITC), University of Twente, Enschede, The Netherlands
}

\section{A R T I C L E I N F O}

\section{Article history:}

Received 3 September 2014

Received in revised form 21 October 2014

Accepted 24 October 2014

Available online 24 November 2014

\section{Keywords:}

Thermal infrared

Land surface temperature

Directional anisotropy

SCOPE

Thermal remote-sensing

\begin{abstract}
A B S T R A C T
This study assesses the performance of the SCOPE model (Van der Tol et al., 2009) to reproduce directional anisotropy of remote sensing thermal infrared measurements. A calibration/validation exercise over two datasets (winter wheat and young pine stand) on energy balance fluxes is presented. Surface sensible and latent heat fluxes are correctly simulated (with RMSE in the range of $30-50 \mathrm{~W} \cdot \mathrm{m}^{-2}$ ) together with directional temperatures in 4 different viewing geometries (RMSE $<1.4 \mathrm{~K}$ ) for both canopies. The sensitivity of the model to two critical but uncertain parameters, the maximum carboxylation capacity $V_{\text {cmo }}$, and a stomatal parameter $\lambda$ (the marginal water cost of carbon assimilation) is discussed; it is shown that anisotropy displays limited sensitivity to both parameters for the experimental conditions met over a well-watered wheat field. The ability of SCOPE to simulate anisotropy is finally illustrated by a qualitative comparison against experimental measurements obtained over a mature pine stand using an airborne TIR camera. SCOPE-simulated TIR directional anisotropy appears to be consistent with the experimental data.
\end{abstract}

(C) 2014 Elsevier Inc. All rights reserved.

\section{Introduction}

Thermal infrared (TIR) satellite data represent an essential source of information to estimate surface fluxes with the scope of monitoring agro-ecosystems and assessing their water status, a large range of applications being found in the fields of agriculture, hydrology and meteorology particularly. However TIR measurements are prone to strong directional anisotropy (we define it as the difference between off-nadir and nadir temperature measurements) and 'hot spot' effects possibly reaching up to $10{ }^{\circ} \mathrm{C}$ and even more in the case of row crops such as vineyards (Lagouarde, Dayau, Moreau, \& Guyon, 2014). The experimental evidence of TIR directional anisotropy has widely been reported on various surface types, vegetation (Balick \& Hutchinson, 1986; Fuchs \& Kanemasu, 1967; Kimes \& Kirchner, 1983; Lagouarde, Ballans, Moreau, Guyon, \& Coraboeuf, 1995, 2000; Lagouarde, Kerr, \& Brunet, 1995; Luquet, Bégué, Vidal, Clouvel, et al., 2003; Nielsen, Clawson, \& Blad, 1984; Paw, Ustin, \& Zhang, 1989) or urban areas for instance (Lagouarde et al., 2012; Voogt \& Oke, 1998). Modeling efforts briefly discussed below have been developed in parallel. Practical applications based on TIR remotely sensed data obviously require the anisotropy to be assessed and corrected.

E-mail address: clement.duffour@bordeaux.inra.fr (C. Duffour).

1 Tel. +33557122432 .
Efforts are currently being made to propose new missions combining high spatial resolution ( $<100 \mathrm{~m}$ ) and high revisit capacities (a few days) such as MISTIGRI (Lagouarde et al., 2013a), HyspIRI (Abrams \& Hook, 2013) or the forthcoming THIRSTY project developed in cooperation between NASA in the USA and the France space agency CNES (Crebassol et al., 2014). In this context the data processing algorithms adapted to these missions must be prepared from now on. The Sunsynchronous orbits of MISTIGRI and THIRSTY have been conceived to allow observing the same site at ground with the same viewing geometry. This minimizes the impacts of directional anisotropy, at least for temporal analysis purposes at a given location, although it cannot eliminate the contribution related to the variations of solar position throughout the year. An accurate assessment of the anisotropy nevertheless remains mandatory as soon as one wants to analyze energy balance or map evapotranspiration across the swath of the image or to compare different fields at regional, because of differences in viewing geometry depending on their location, to which differences in time, i.e. sun position, may add as a result of a swath width reaching about $900 \mathrm{~km}$ with THIRSTY.

Another motivation lies in activities of calibration/validation of satellite data and products. Indeed in-situ measurements are often performed using infrared radiometers aiming at a surface sample which size - generally a few meters - is chosen to take into account the small scale spatial variability of the sample, and to retrieve a temperature measurement considered to be 'representative' of the studied 
surface. Nevertheless anisotropy complicates direct comparison of insitu measurements to satellite data because (i) experimental setups are generally not designed to perform measurements in the same viewing direction as the satellite, and because (ii) the radiometer operates an integration of several directional temperatures within its FOV (field of view) whereas the space sensor 'sees' the surface in a unique direction. Cal/val exercises should therefore rely on accurate models of TIR directional anisotropy.

Today no operational method is available to correct for directional anisotropy in the processing of surface temperature products (level 2 or more). A number of approaches have nevertheless been proposed to simulate directional temperatures over different surface types. They require as input data too many pieces of information not easily accessible by remote sensing and/or parameters requiring specific calibration. Indeed, similarly to the surface temperature, the directional anisotropy results from the coupled energy and radiative transfers within the canopies and depends on a lot of factors: the canopy structure governs the distribution of sunlit (i.e. warmer) and shaded (i.e. colder) elements seen by the sensor in a given direction, but it also governs through energy transfers the temperature profiles within the vegetation or on the facets of discontinuous or row crops; the water status and some physiological parameters are also a critical factor (Fuchs \& Tanner, 1966), and meteorological conditions, wind speed in particular, play a significant role not yet enough documented to our knowledge. Some models have been developed with the objectives of retrieving the component temperatures of the canopies from directional measurements either using simple geometrical descriptions of the canopies, for instance for row crops (Caselles \& Sobrino, 1989; Kimes, 1983) or homogeneous canopies (Olioso, 1992; Timmermans, Verhoef, van der Tol, \& Su, 2009). More sophisticated approaches based either on multilayer models or 3D-models were developed to better describe the processes governing directional temperatures and emissivity and to perform sensitivity studies (Guillevic, 2003; Luquet et al., 2004; Norman, 1979; Van der Tol et al., 2009).

Only few authors focused on the correction of satellite data. Pinheiro, Privette, Mahoney, and Tucker (2004) showed that the observation geometry of the National Oceanic and Atmospheric Administration (NOAA) Advanced Very High Resolution Radiometer (AVHRR) implies directional effects which can be related to fraction cover of shaded and sunlit elements of the scene. Rasmussen, Gottsche, Olesen, and Sandholt (2011) compared the Meteosat Second Generation observation geometry to nadir view over savannas and they found differences larger than $1{ }^{\circ} \mathrm{C}$ during the day, which cannot be neglected. Guillevic et al. (2013) put into evidence the difficulty of the comparison of different satellite LST products because of the effects of anisotropy.

In this framework it appears necessary to develop simple methods adapted to the routine processing of data from space. These could be statistical approaches such as kernel models (Snyder and Wan, 1998). All of them require important volumes of reliable anisotropy data to be available to be built and calibrated. Experimental data are too scarce and limited to only a few surfaces and conditions to be used for this purpose. An alternative approach can be based on a robust deterministic model helping in a first step to identify the variables and surface parameters to which the directional anisotropy displays the highest sensitivity, and in a second step used as a data generator to derive and calibrate simpler methods. The paper focuses on the first step and is based on the SCOPE (Soil Canopy Observation, Photochemistry and Energy fluxes) model (Van der Tol et al., 2009) developed for continuous vegetation. This was selected both for its realism confirmed in several previous studies where it was used for its ability to simulate energy fluxes (Denis, 2013; Timmermans et al., 2011) or chlorophyll fluorescence (Lee et al., 2013) and for its interest for remote sensing applications as it includes a detailed modeling of the coupled energy and radiative transfer within the vegetation, and derives up to the outgoing radiances in a large range of wavelengths. After a brief description of the model, an evaluation of the model against field data will be presented. Its potential for simulating the directional anisotropy in a wide range of viewing geometries will finally be illustrated, and the perspectives opened to develop operational methods of directional effects correction will be discussed.

\section{SCOPE (soil canopy observation of photochemistry and energy fluxes)}

The SCOPE model (Van der Tol et al., 2009) was developed for the combined simulation of directional TOC (Top Of Canopy) reflected solar radiation, emitted thermal radiation and sun-induced fluorescence signals together with energy, water and $\mathrm{CO}_{2}$ fluxes. It is based on a combination of several models describing radiative, turbulent and mass transfers inside the canopy, taking into account leaf biochemistry processes. The main features of the model are briefly recalled here, and for more details, the reader is referred to the original paper.

Considering radiative transfer calculations, the scene is described with 60 canopy layers of equal leaf area, and one soil layer. In each of them, discrimination is made between shaded and sunlit parts (leaves or soil). The orientations of leaves are characterized with 13 zenithal $\left(\theta_{l}\right)$ and 36 azimuthal angles $\left(\varphi_{l}\right)$. The leaf angle distribution function of $\theta_{l}$ depends on the vegetation type. The unified 4SAIL model (Verhoef, Jia, Xiao, \& Su, 2007) allows to compute extinction coefficients and to derive gap fractions. The radiative transfer is computed on the $0.4-50 \mu \mathrm{m}$ range of wavelengths.

An energy budget is solved separately for sunlit and shaded parts of each layer; an iterative process with a convergence criterion on the residual of the energy budget allows computing the corresponding surface temperatures. The net radiation $R_{\mathrm{n}}$ is computed by combining the components of incident radiation (shortwave and longwave) together with the 4SAIL derived optical and thermal contributions with the Stefan-Boltzmann emittance within the layer. In the thermal infrared domain, uniform emissivity values are prescribed for the vegetation and the soil. The PROSPECT model (Jacquemoud \& Baret, 1990) allows computing the optical properties of vegetation (transmittance and reflectance spectra), which require several characteristics of leaves to be known, such as their chlorophyll $\left(C_{\mathrm{ab}}\right)$, dry material $\left(C_{\mathrm{dm}}\right)$, water $\left(C_{\mathrm{w}}\right)$ and senescent material concentrations and thickness parameter $(N)$. Directly measured spectra can also be used as an alternative. The same spectrum is used for all leaves, independently of their position in the canopy. A soil reflectance spectrum must also be prescribed.

The sensible $(H)$ and latent $(L E)$ heat fluxes are classically calculated for each layer, and for shaded and sunlit leaves (resp. soil), from the vertical gradients of temperature and humidity between the considered layer and the reference level of meteorological measurements above the canopy. The net leaf $\mathrm{CO}_{2}$ assimilation rate $A$ is computed simultaneously from Farquhar, von Caemmerer, and Berry (1980). The aerodynamic resistance is taken from Wallace and Verhoef (2000). An aerodynamic resistance is calculated for the soil and for the canopy each time step as a function of LAI, canopy height, wind speed and atmospheric stability. This resistance holds for all leaves (no differentiation is made according to position of a leaf in the canopy). The stomatal resistance $\left(r_{\mathrm{s}}\right)$ is calculated after Cowan (1977) and requires some biochemical parameters to be known (the stomatal resistance formulation has been modified in a later version of SCOPE, but we use the original published model, see Van der Tol's paper for details).

In what follows (Section 4), a particular attention will be paid to two of these, the maximum of carboxylation $\left(V_{\mathrm{cmo}}\right)$ and marginal cost of assimilation $(\lambda)$, which control the photosynthetic capacity and describe the compromise between the loss of water by transpiration and uptake of $\mathrm{CO}_{2}$ through stomatal cavities respectively. At the ground level, a storage heat flux $G$ is estimated as the residual of the energy budget equations for shaded and sunlit soil, and the corresponding surface temperatures are computed using a classic force-restore approach (Bhumralkar, 1975), with soil surface resistance and thermal inertia either computed from water content or prescribed. 
The model is run at the time step of the meteorological input variables. These are the air temperature and vapor pressure, the wind speed, and the components of downward shortwave and longwave radiation. The atmospheric radiative transfer model MODTRAN (Berk et al., 1999) then allows to compute the spectral distribution of these latter. The outputs of the SCOPE model are the net radiation and energy fluxes, the aerodynamic sunlit/shaded temperature profiles within the canopy and at ground level and the TOC radiances.

\section{Data sets}

The calibration and the evaluation of SCOPE were performed using experimental data over winter wheat and young pine from two sites, Avignon and Bilos. Data from a third site, Le Bray, were used to illustrate the ability of the model to simulate the directional anisotropy of TIR signals.

\subsection{Avignon winter wheat dataset}

A wheat dataset was collected over a 1.8 ha flat agricultural field at the INRA Research Center in Avignon located at $43^{\circ} 55^{\prime} 00^{\prime \prime} \mathrm{N}, 4^{\circ} 52^{\prime}$ 47" E, from January to April 2006. This site was devoted to several objectives dealing with the development and the test of crop models, soilvegetation-atmosphere transfer models and remote sensing algorithms. The site was included in the CARBOEUROPE-IP network (http://www. carboeurope.org/) since 2004. It is now part of the ICOS (Integrated Carbon Observation System - http://www.icos-infrastructure.eu/) France project. The region was characterized by a typical Mediterranean climate and the crops were grown on a silty clay loam soil. Irrigation is performed when required, which confers to the soil uniform very high moisture. The radiative components of net radiation were continuously measured, using Kipp \& Zonen CMP21 pyranometer, CG4 pyrgeometer and CNR1 instrument (for solar irradiance, longwave irradiance and net radiation, respectively). $\mathrm{H}_{2} \mathrm{O}$ and $\mathrm{CO}_{2}$ surface-atmosphere fluxes were measured using the eddy covariance methodology (according to the methodology proposed by Aubinet et al. (2000) for CARBOEUROPE-IP) with a Young 81000 sonic anemometer and a LiCor 7500 open path analyzer. As the field was not very large, the positions for eddy-covariance measurements were optimized in order to reduce the effects of advection by considering the directions of major wind regimes and by setting the instruments about $1 \mathrm{~m}$ above the canopy top. A footprint analysis indicated that $90 \%$ of the fluxes originated from the field, accounting for more than $90 \%$ of the data acquired in diurnal conditions (analysis performed with the footprint model proposed by Hsieh, Katul, and Chi (2000)). Two thermal infrared radiometers Heitronics KT15.82D were installed to measure the brightness surface temperature of the wheat crop. One was aiming towards South at a zenith angle of $18^{\circ}$ (called $\mathrm{Tb}_{18}$ ), and its companion approximately towards North ( $10^{\circ}$ from North clockwise) in the direction of rows, at a zenith angle of $55^{\circ}$ (called $\mathrm{Tb}_{55}$ ). The FOV of both instruments was $28^{\circ}$.

Crop structure and biomass, canopy reflectances, soil moisture and temperature were monitored in parallel. Vegetation height $\left(h_{\mathrm{c}}\right)$ was estimated almost once a week as the average height of 15 individual plants. It varied between 0.15 and $0.47 \mathrm{~m}$ during the period of measurements. The LAI was measured using a LICOR 3000 planimeter and hemispherical photographs processed with the Can-Eye software (developed at INRA Avignon, see http://www.paca.inra.fr/can-eye/CAN-EYE-Home/ Welcome). It increased from 0.6 up to 5.5 during the crop growth. A standard meteorological station from the INRA-Agroclim network was also available (https://www.paca.inra.fr/agroclim). The surface soil moisture of the $0-5 \mathrm{~cm}$ top soil layer was determined integrating the measurements from 3 capacitive probes and regularly checked against gravimetric samples.

All the data were averaged on $30 \mathrm{~min}$ time steps. Careful calibrations of the instruments were performed and specific procedures for checking the validity of the recorded data were used (cross-checking data from several instruments, comparison to standard and statistical models).

\subsection{Bilos young pine stand}

This site is located $\left(44^{\circ} 29^{\prime} 38.08^{\prime \prime} \mathrm{N} ; 0^{\circ} 57^{\prime} 22^{\prime \prime}\right.$ W) $50 \mathrm{~km}$ South-West of Bordeaux (France) and is part of the FLUXNET network since the year 2004. As for Avignon it is now part of the ICOS France project. The maritime pine (Pinus pinaster Ait.) stand was 5 and 6 years old in 2010 and 2011 respectively. The pines were planted on a sandy soil in rows with $4 \mathrm{~m}$ spacing. Their mean height was $2.5 \mathrm{~m}$ (2010) and $\sim 3.5 \mathrm{~m}$ (2011) at the time of measurements. The inter-row vegetation was very dense and covered with a mixture of gorse (Ulex minor, Roth), heather (Calluna vulgaris L.) and other herbaceous plants (Molinia coeruela M., Phytolacca americana L.) reaching nearly the same height as the trees. The assumption of the whole canopy being a homogeneous vegetation layer is therefore quite realistic (Fig. 1a). In 2010 the total LAI of the canopy is $\sim 2 \mathrm{~m}^{2} \cdot \mathrm{m}^{-2}$ with a partition of about $0.7 \mathrm{~m}^{2} \cdot \mathrm{m}^{-2}$ for trees and $1.3 \mathrm{~m}^{2} \cdot \mathrm{m}^{-2}$ for the inter-row vegetation. In 2011 LAI falls to $1.5 \mathrm{~m}^{2} \cdot \mathrm{m}^{-2}$ because the understory was thinned. Two CE180 pyranometers (Cimel Electronique) were measuring the incident and reflected short-wave irradiance, and a CGR2 pyrgeometer (Kipp \& Zonen) was providing the incident and reflected long-wave irradiances. The net radiation $\left(R_{\mathrm{n}}\right)$ was measured with an NrLite pyradiometer (Kipp

\section{a}
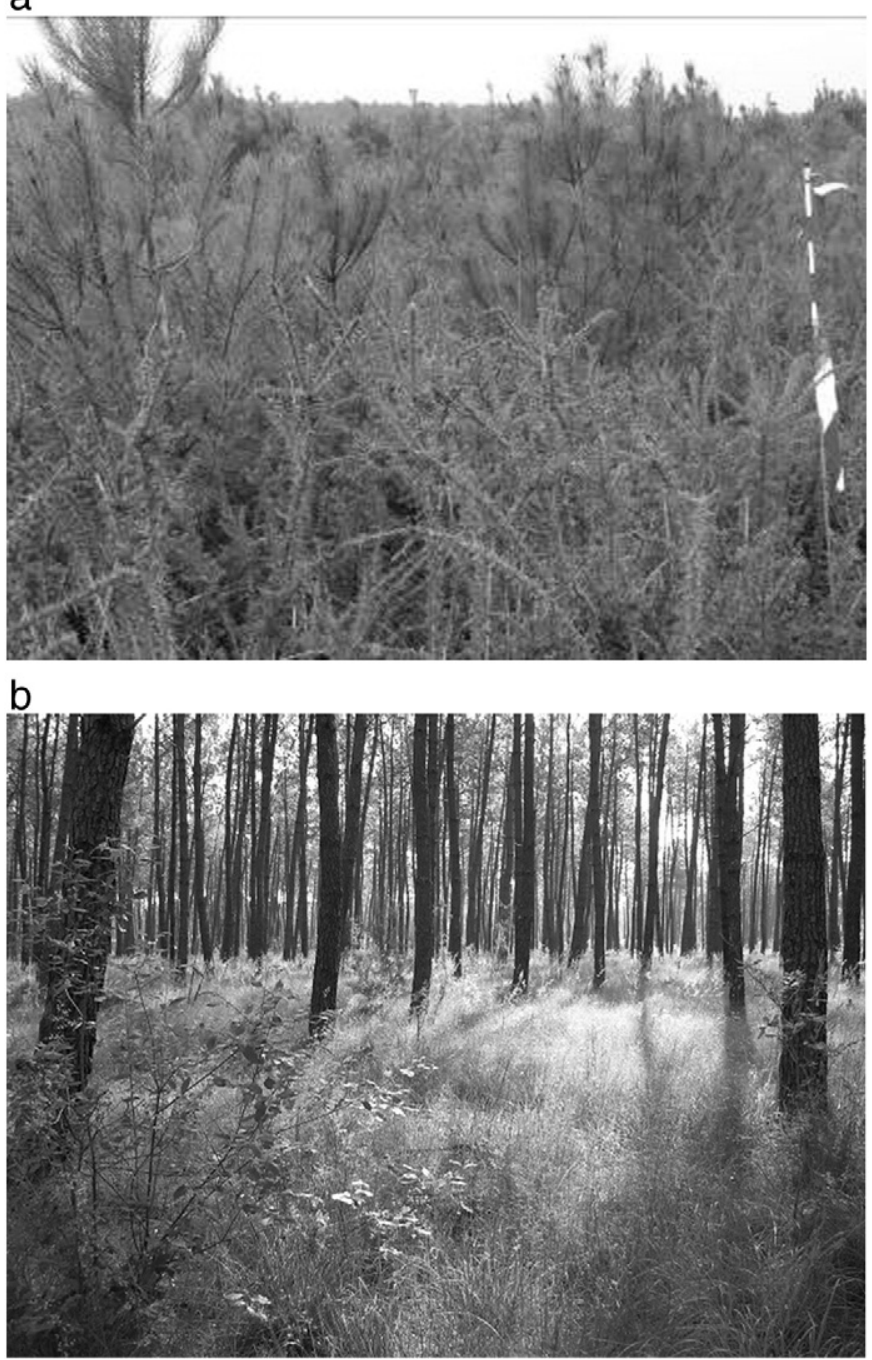

Fig. 1. Bilos young pine stand (a) and Le Bray mature pine stand (b). 
\& Zonen) calibrated against a CNR4 net radiometer (Kipp \& Zonen). The sensible and latent heat and $\mathrm{CO}_{2}$ fluxes were measured using the eddy covariance method with a sonic anemometer (model 1210 R3; Gill Instruments) and a LiCOR 7500 open-path analyzer. These instruments were mounted at the top of a $6.4 \mathrm{~m}$ tower, $~ 3 \mathrm{~m}$ above the canopy. The stand size being very large (about 50 ha), the fetch conditions were excellent. All the data were averaged on 30 min time steps.

Two sets of directional temperature measurements performed in 2010 and 2011 in different viewing configurations were acquired using a Heitronics KT15.82D infrared radiometer placed in aluminum shelter to avoid intense heating from the sun. Calibration tests performed at the laboratory previously to the ground measurements revealed good stability of the response of the instrument. From October to December 2010, the radiometer was first mounted on a motorized platform piloted to follow the sun course during the day, so continuously providing a temperature measurement in the direction of the hot spot. In a second phase, from August 2011 to the end of the year, the brightness surface temperature was measured at a $27^{\circ}$ zenith angle aiming towards West, in the row direction. The FOV of both instruments was $28^{\circ}$.

\subsection{Le Bray mature pine stand}

Contrary to the two previous sites, Le Bray site was not devoted to the validation of SCOPE. Although the structure of the canopy did not fit the assumption of homogeneous canopy (Fig. 1b) made in SCOPE, this site was used in the framework of this study to illustrate the ability of SCOPE to simulate the TIR directional anisotropy thanks to the high quality measurements of TIR directional effects performed in 1996 (Lagouarde et al., 2000). The site was located at about $20 \mathrm{~km}$ from Bordeaux $\left(44^{\circ} 43^{\prime} 01.50^{\prime \prime} \mathrm{N}, 0^{\circ} 46^{\prime} 09.0^{\prime \prime} \mathrm{W}\right)$ and consisted of a large $460 \times 320 \mathrm{~m}$ stand of 25 year old (in 1995) mature maritime pine (Pinus pinaster Ait.) planted on a humid moorland. This site was also part of different networks devoted to carbon studies and equipped with a complete eddy covariance system mounted at the top of a $27 \mathrm{~m}$ scaffold. It included a 3D sonic anemometer (Solent R2, Gill instruments) for sensible heat fluxes, wind speed and friction velocity and a sonic anemometer coupled with an infrared gas analyzer (Li-6262, LICOR) for $\mathrm{CO}_{2}$ and water vapor fluxes. The mean height of trees was $17.6 \mathrm{~m}$. The rows were roughly ENE-WSW with a $30^{\circ}$ azimuth orientation. The mean spacing of trees was about $4.5 \mathrm{~m}$, and their density about 500 stems/ha. The LAI remained rather constant, about 3.1 in midsummer. The crown cover was estimated to be about $70 \%$, leaving the understory herbaceous vegetation (Molinia caerulea) partly visible.

Airborne TIR camera measurements were carried out on September 4th 1996 at different hours of the day (11:20-11:52, 12:52-13:36 and 15:38-16:08 UTC) providing several full directional anisotropy polar plots, in all azimuth directions and up to $55^{\circ}$ zenith viewing angles. For details about the experimental setup and the methodology to derive the directional effects, the reader is referred to the paper by Lagouarde et al. (2000).

\section{Calibration and evaluation of the model vs. energy and mass fluxes}

\subsection{Calibration strategy}

The calibration of SCOPE was performed by comparing simulated evapotranspiration and $\mathrm{CO}_{2}$ fluxes against the available measurements. Surface temperature data were kept to perform an independent evaluation of the capacity of SCOPE for simulating thermal infrared signals. Only two parameters were retrieved through the calibration procedure, the maximal carboxylation capacity $\left(V_{\mathrm{cmo}}\right)$ and the marginal cost of assimilation $(\lambda)$. First, a literature review revealed that these parameters, which are used in the Cowan's model to compute the stomatal resistance, have a major influence on photosynthesis and transpiration processes. Second, the possibility to prescribe these parameters from other source of information is limited: it might be possible for $V_{\mathrm{cmo}}$ from leaf nitrogen content (Wilson, Baldocchi, \& Hanson, 2000; Xu \& Baldocchi, 2003), but this relied only on few experimental results and confirmation is still needed. It was almost impossible to set values for $\lambda$ since possible determinants have not been clearly identified up to now. The other parameters needed in SCOPE were considered either to be known or to be parameterized from other variables with enough confidence. The calibration process was performed only on clear days and one daily value of $V_{\mathrm{cmo}}$ and $\lambda$ was determined using daytime data only. Daily values rather than seasonal values have been calibrated, because the parameters may exhibit seasonal cycles. Cloudy days and nighttime observations were eliminated from the calibration process because of the low parameter sensitivity due to the low levels of available energy and fluxes. Moreover, in nighttime conditions, the uncertainties in the parameterization of stable atmospheric conditions may generate ill-convergence in the turbulent transfer calculations which impair the calibration process.

The calibration computations themselves have been performed using the automatic optimization "fminsearch" procedure, proposed in the MATLAB optimization toolbox. It is a multidimensional unconstrained non-linear minimization procedure, based on the Simplex algorithm (Nelder \& Mead, 1965). The Simplex algorithm explores the inputs space to find out a combination that minimizes a cost function. It tests adjacent parameter sets of the feasible space in sequence so that at each new set the objective function improves or is unchanged. The procedure starts with an initial value of the input set of parameters that must be calibrated. The initial values prescribed were $80 \mu \mathrm{mol} \cdot \mathrm{m}^{-2} \cdot \mathrm{s}^{-1}$ and $700 \mathrm{~mol} \cdot \mathrm{mol}^{-1}$ for $V_{\text {cmo }}$ and $\lambda$ respectively.

The Simplex method is very efficient in practice and is widely used in model parameter retrieval studies. The cost function to be minimized was the mean of the two relative root mean square errors calculated between the model and the observed variables with the following:

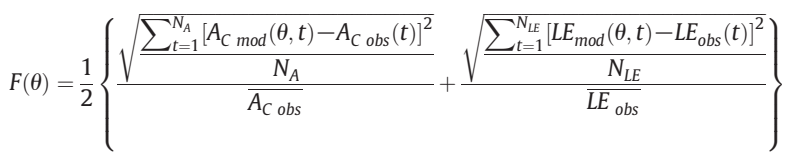

where $F(\theta)$ is the cost-function evaluated for a candidate set of input parameters $\theta=\left\{V_{\mathrm{cmo}}, \lambda\right\}, A_{\text {Cobs }}$ and $L E_{o b s}$ respectively the observed net ecosystem exchange of $\mathrm{CO}_{2}$ and the evapotranspiration flux, $A_{C \bmod }$ and $L E_{\text {mod }}$ are respectively the modeled net ecosystem exchange of $\mathrm{CO}_{2}$ and the modeled evapotranspiration flux, and $N_{A}$ and $N_{L E}$ the numbers of available daily observations $A_{o b s}$ and $L E_{o b s}$, respectively. The two right terms in the cost function were normalized using the mean of the observations in order to give them a similar weight in the calculation. In this study, a termination tolerance on the cost function of $10^{-2}$ and a maximum number of iterations of 100 were considered as breaking criteria in order to stop the iterative procedure of the 'fminsearch' function.

\subsection{Model implementation/SCOPE input parameters}

The input parameters used in the calibration phase for both Avignon (wheat crop) and Bilos (pine stand) sites are gathered in Table 1. The leaf angle distribution was assumed spherical for both types of vegetation canopy. For wheat, detailed biological measurements combined with ancillary information on vegetation properties allowed to compute leaf reflectance and transmittance spectra in the solar domain using the PROSPECT model. For maritime pine, spectra measured by Berbigier and Bonnefond (1995) were used. In the thermal infrared, a same arbitrarily but realistic 0.03 value was used for leaves reflectance (i.e. 0.97 emissivity) and the transmittance was assumed to be 0 (Gerber et al., 2011; Olioso, 1995). 
Table 1

Values of the main input parameters used in SCOPE.

\begin{tabular}{|c|c|c|c|}
\hline & $\begin{array}{l}\text { Avignon } \\
\text { Wheat }\end{array}$ & $\begin{array}{l}\text { Bilos } 2010 \\
\text { Maritime pine }\end{array}$ & $\begin{array}{l}\text { Bilos } 2011 \\
\text { Maritime pine }\end{array}$ \\
\hline \multicolumn{4}{|l|}{ Vegetation parameters } \\
\hline LAI & $0.6-5.5$ & 2 & 1.5 \\
\hline$h_{\mathrm{c}}(\mathrm{m})$ & $0.15-0.47$ & 2.5 & 3.5 \\
\hline LADFa & -0.35 & -0.35 & -0.35 \\
\hline LADFb & -0.15 & -0.15 & -0.15 \\
\hline$C_{\mathrm{ab}}\left(\mu \mathrm{g} \cdot \mathrm{cm}^{-2}\right)$ & 60 & \multirow{2}{*}{\multicolumn{2}{|c|}{ Measured spectrum of needles (Berbigier \& Bonnefond, 1995) }} \\
\hline$C_{\mathrm{dm}}\left(\mathrm{g} \cdot \mathrm{cm}^{-2}\right)$ & 0.012 & & \\
\hline$C_{\mathrm{w}}(\mathrm{cm})$ & 0.09 & & \\
\hline$C_{\mathrm{s}}$ & 0 & & \\
\hline$N$ & 1.4 & & \\
\hline$\rho$ thermal & 0.03 & 0.03 & 0.03 \\
\hline$\tau$ thermal & 0.00 & 0.00 & 0.00 \\
\hline$w(\mathrm{~m})$ & 0.01 (Dornbusch et al., 2011) & 0.1 & 0.1 \\
\hline \multicolumn{4}{|l|}{ Biochemical parameters } \\
\hline$V_{\mathrm{cmo}}\left(\mu \mathrm{mol} \cdot \mathrm{m}^{-2} \cdot \mathrm{s}^{-1}\right)$ & Calibrated & Calibrated & Calibrated \\
\hline$\lambda$ & Calibrated & Calibrated & Calibrated \\
\hline \multicolumn{4}{|l|}{ Soil parameters } \\
\hline$r_{\mathrm{ss}}\left(\mathrm{s} \cdot \mathrm{m}^{-1}\right)$ & Olioso (1992) & 2000 & 500 \\
\hline$\Gamma\left(\mathrm{J} \cdot \mathrm{m}^{-2} \cdot \mathrm{K}^{-1} \cdot \mathrm{s}^{-1 / 2}\right)$ & Van de Griend and O'Neill (1986) & 900 & 900 \\
\hline
\end{tabular}

The width of wheat leaves $(w)$ was set at $1 \mathrm{~cm}$, so that the average ratio $w / h_{\mathrm{c}}$ governing the hot spot shape was about $3 \cdot 10^{-2}$. For pine, as the hot spot shape is likely to depend more directly on the size of shoots than on the size of needles (Jupp \& Strahler, 1991), $w$ was arbitrarily set to $10 \mathrm{~cm}$ in the calibration exercise to preserve the $3 \cdot 10^{-2} w / h_{\mathrm{c}}$ ratio. The effect of the $w / h_{\mathrm{c}}$ ratio will be addressed in more details in Section 6 .

In the wheat field, the $0-5 \mathrm{~cm}$ top soil layer soil moisture $\theta_{0-5}$ provided to the model as an input variable allowed to compute the of the soil resistance to vapor transfer $r_{\mathrm{ss}}$ and the soil thermal inertia $\Gamma$ using formulations proposed by Olioso et al. (1999) and Van de Griend and O'Neill (1986) respectively:

$r_{s s}=1.439 \cdot 10^{5}\left(\theta_{\text {sat }}-\theta_{0-5}\right)$

where $\theta_{\text {sat }}$ is the soil water content at saturation $\left(\mathrm{m}^{3} \cdot \mathrm{m}^{-3}\right)$. This equation was calibrated on simulations of soil evaporation for a similar soil type performed with a detailed soil water transfer model (based on Richard's equations accounting for coupled heat and water transfer and for vapor transfers in the soil top layers; Olioso, 1992).

$\Gamma=3516 \cdot \theta_{0-5}+841$

No similar soil moisture data being available for Bilos site, the typical values of $2000 \mathrm{~s} \cdot \mathrm{m}^{-1}$ and $500 \mathrm{~s} \cdot \mathrm{m}^{-1}$ prescribed in SCOPE for dry and wet conditions respectively met in 2010 and 2011 were used for soil resistance. The soil thermal inertia was given an average value $\left(\sim 900 \mathrm{~J} \cdot \mathrm{m}^{-2} \cdot \mathrm{K}^{-1} \cdot \mathrm{s}^{-1 / 2}\right)$ estimated as $\sqrt{\rho_{s} C_{s} \lambda_{s}}$, with density $\rho_{\mathrm{s}}=1600 \mathrm{~kg} \cdot \mathrm{m}^{-3}$, specific heat $C_{s}=1000 \mathrm{~J} \cdot \mathrm{kg}^{-1} \cdot \mathrm{K}^{-1}$ and heat conductivity $\lambda_{s}=0.5 \mathrm{~W} \cdot \mathrm{m}^{-1} \cdot \mathrm{K}^{-1}$.

\subsection{Results of SCOPE calibration}

The time evolution of the retrieved values of $V_{\mathrm{cmo}}$ and $\lambda$ is presented in Fig. $2 \mathrm{a}$ and b. For wheat $V_{\mathrm{cmo}}$ increased from winter $\left(\sim 100 \mu \mathrm{mol} \cdot \mathrm{m}^{-2} \cdot \mathrm{s}^{-1}\right)$ to spring $\left(\sim 150 \mu \mathrm{mol} \cdot \mathrm{m}^{-2} \cdot \mathrm{s}^{-1}\right)$, then decreased to summer $\left(\sim 100 \mu \mathrm{mol} \cdot \mathrm{m}^{-2} \cdot \mathrm{s}^{-1}\right)$.

The values found for pine were in the same orders of magnitude and were very consistent with the ones given in Ogée, Brunet, and Loustau (2003) and Porté and Loustau (1998) for an older maritime pine stand. Values of $\sim 50 \mu \mathrm{mol} \cdot \mathrm{m}^{-2} \cdot \mathrm{s}^{-1}$ are observed between the middle of summer and winter over the 2011 Bilos data set. Moreover, retrieved winter $V_{\text {cmo }}$ values on this site in 2010 and 2011 agreed rather well. The important noise observed in the time evolution of $V_{\mathrm{cmo}}$ in all cases, was likely to be related to numerical uncertainties in the inversion process. Despite a few contradictory results found in literature, such as those of Grossman-Clarke et al. (1999) who reported high values of $V_{\mathrm{cmo}}$ in
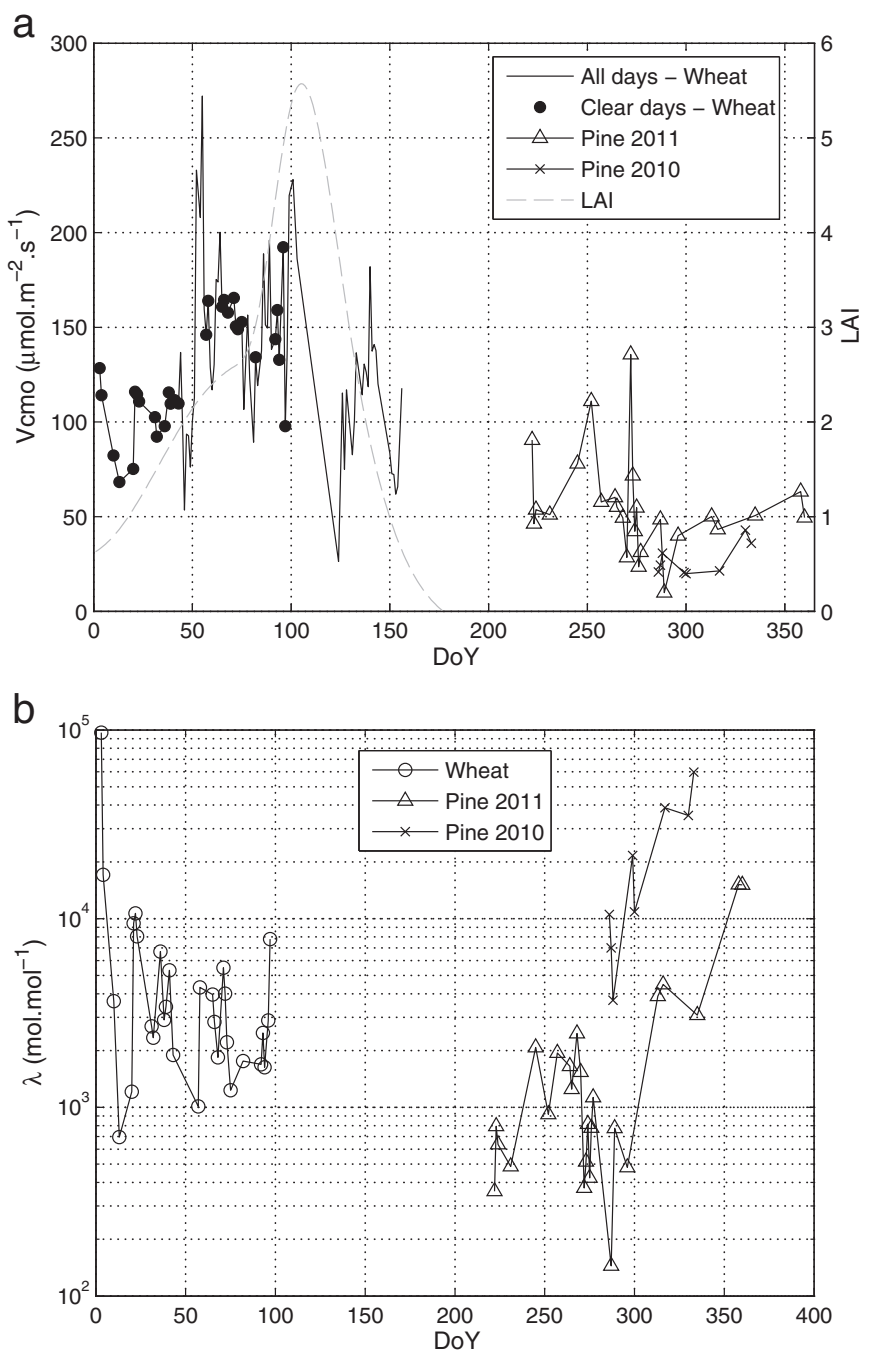

Fig. 2. Retrieved $V_{\text {cmo }}(\mathrm{a})$ and $\lambda$ (b) versus day of year for each site. 

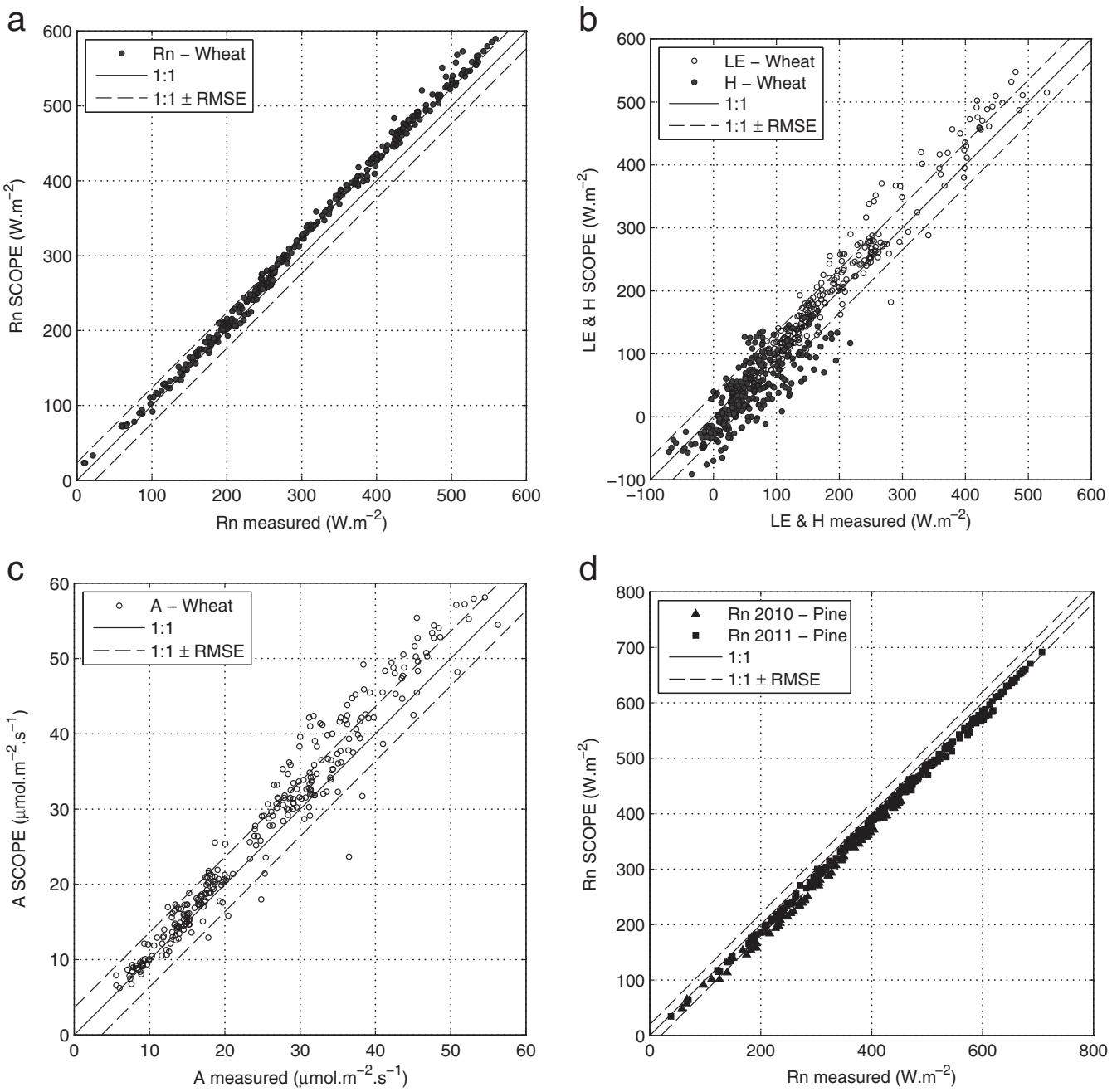

d
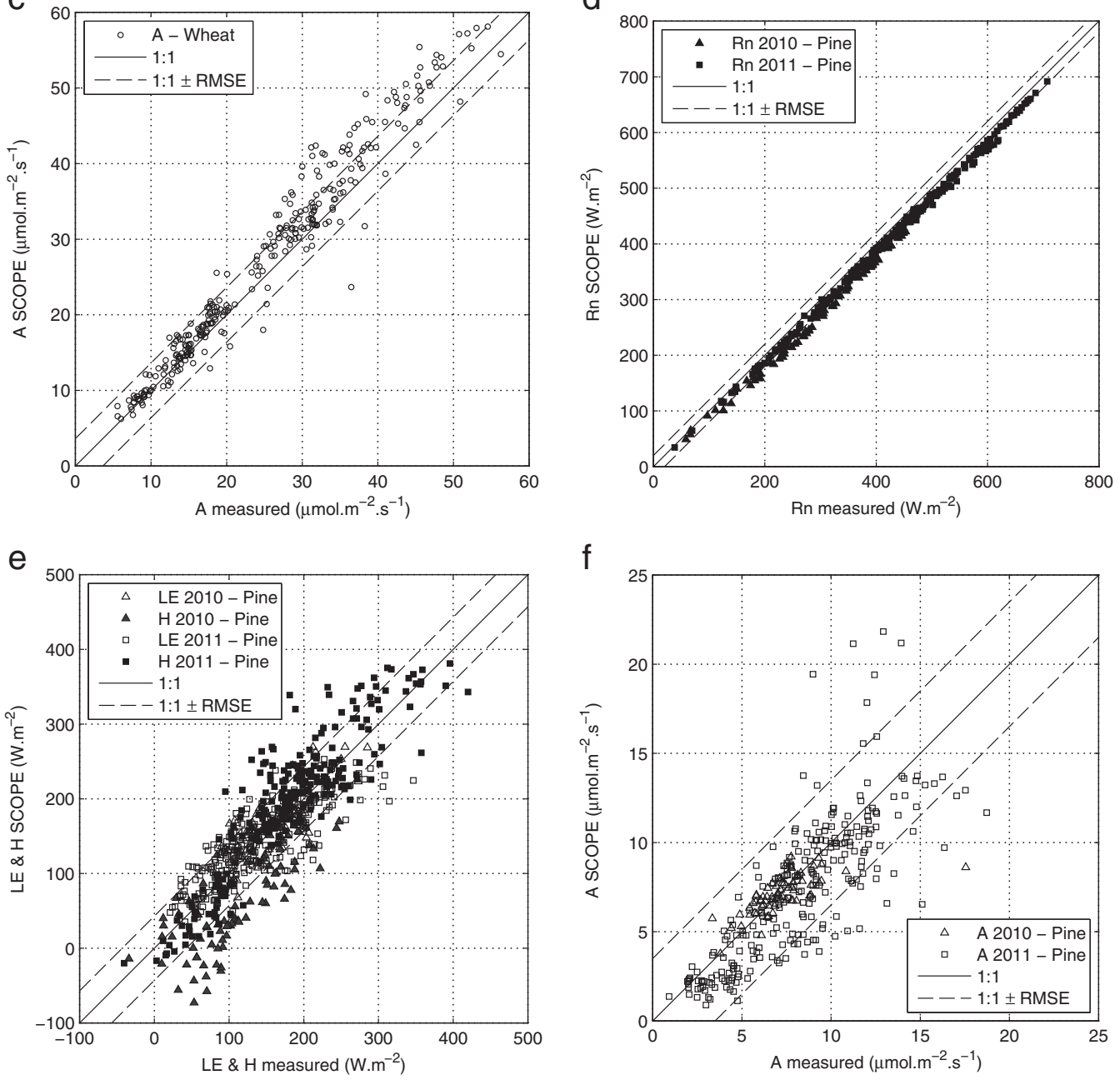

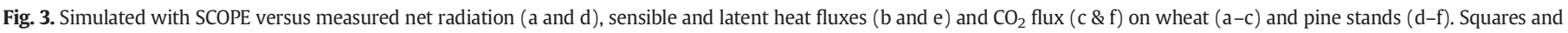

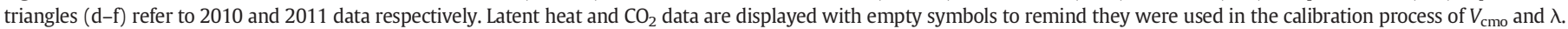

winter for wheat, the values of $V_{\mathrm{cmo}}$ we obtained were in the range of widely accepted values (Bunce, 2000; Leuning, Kelliher, de Pury, \& Schulze, 1995; Medlyn et al., 2002; Xu \& Baldocchi, 2003). The seasonal variations we found for wheat seems to be quite well correlated to LAI evolution (Fig. 2a), and are consistent with the results of $\mathrm{Xu}$ and Baldocchi (2003) for an oak species. However, although the role of $V_{\text {cmo }}$ is very well known, its determinism is not clearly understood yet. For instance, some of the above-cited studies showed that the influence of temperature could also be large (see Leuning, 2002; Medlyn et al., 2002; Weis \& Berry, 1988), and that $V_{\text {cmo }}$ could decrease with soil drying and leaf nitrogen content (Grossman-Clarke et al., 1999; Wilson et al., 2000; Xu \& Baldocchi, 2003). We modeled none of these effects explicitly, such that any regulation of $V_{\mathrm{cmo}}$ should appear in the optimized values while leaf nitrogen content, temperature and soil moisture varied over 
the season. This variability could partly explain the noise in Fig. 2a, on top of the noise inherent to micrometeorological observations with a varying footprint.

Retrieved marginal cost of assimilation $\lambda$ is in an acceptable range (Fig. 2b). Despite high values obtained at the beginning of the year, the mean of the retrieved $\lambda$ is $3700 \mathrm{~mol} \cdot \mathrm{mol}^{-1}$ for wheat, which is an acceptable value consistent with literature (Lloyd \& Farquhar, 1994; Schymanski, Roderick, Sivapalan, Hutley, \& Beringer, 2008; Thomas, Eamus, \& Bell, 1999a,b; Van der Tol, Dolman, Waterloo, \& Raspor, 2007). Unrealistically high values of $\lambda$ could be caused by wet canopy conditions after rain or dew. In a wet canopy $\lambda$ has no meaning, because the diffusion of carbon dioxide into the stomata is disconnected from the evaporation flux while intercepted water evaporates. For pine at Bilos in 2011 the mean value is somewhat lower, around $1000 \mathrm{~mol} \cdot \mathrm{mol}^{-1}$, excluding the two values exceeding $10^{4} \mathrm{~mol} \cdot \mathrm{mol}^{-1}$. For the 2010 period the retrieved values of $\lambda$ for pine are very high. A lack of efficiency in the inversion due to low values of fluxes could possibly be invoked here.

\section{Evaluation of the model}

After calibration using the available evapotranspiration and $\mathrm{CO}_{2}$ flux measurements, the quality of simulated radiative and energy fluxes was first assessed. The validation of directional temperatures is presented in a second step. Finally one-at-the-time sensitivity analysis of the fluxes to the calibrated parameters $V_{\mathrm{cmo}}$ and $\lambda$ is made.

\subsection{Evaluation of energy fluxes}

The evaluation of fluxes simulation was performed against data acquired between 10:00 and 15:00 UTC only. As the time step of measurements was $30 \mathrm{~min}, 11$ pairs of flux measurements were available per day. This time interval was chosen because it corresponded to the periods of the day when the surface fluxes reached values with significant level of energy at any time of the year.

The comparison between simulated and measured net radiation $\left(R_{\mathrm{n}}\right.$, sensible heat flux $(H)$ and latent heat of actual evaporation $(L E)$ ) for 30 min time steps is given in Fig. 3, with the corresponding statistics in Table 2 .

For $R_{\mathrm{n}}$, although the simulated values display a $\sim 3 \%$ over-estimation over wheat and a small systematic bias of about $30 \mathrm{~W} \cdot \mathrm{m}^{-2}(2010)$ to $15 \mathrm{~W} \cdot \mathrm{m}^{-2}$ (2011) over pine, the results are considered to be excellent. In the case of winter wheat, the discrepancies could be attributed to the uncertainties on the vegetation parameters introduced in the PROSPECT reflectance model (chlorophyll a and b, dry matter and water concentrations, leaf thickness) which were not available for winter wheat specifically and which were prescribed from the LOPEX 93 data base (Hosgood et al., 1995). For maritime pine the reflectance spectra directly used in SCOPE had been obtained for pine needles (Berbigier \& Bonnefond, 1995), possibly not being quite representative of the reflectance of the whole canopy including the understory.

$L E$ fluxes are also satisfactorily simulated, as expected, $L E$ being used within the calibration process of $V_{\text {cmo }}$ and $\lambda$. The RMSE values found, about $30 \mathrm{~W} \cdot \mathrm{m}^{-2}$ for all sites are better than those classically reported $\left(\sim 60 \mathrm{~W} \cdot \mathrm{m}^{-2}\right)$. The rather low $R^{2}$ value for Bilos in $2010\left(R^{2}=0.55\right)$ can be related to the low range of variation of $L E$. In the same way, $A$ fluxes are very consistent with the measurements since they are used in the calibration process ( $\mathrm{RMSE}<5 \mu \mathrm{mol} \cdot \mathrm{m}^{-2} \cdot \mathrm{s}^{-1}$ ).

Similar results are found for sensible heat fluxes, with RMSE lower than $40 \mathrm{~W} \cdot \mathrm{m}^{-2}$ for wheat and 2011 maritime pine datasets. The result is less satisfactory, even though it remains acceptable, for Bilos in 2010 for which RMSE is $65 \mathrm{~W} \cdot \mathrm{m}^{-2}$ with a bias of $50 \mathrm{~W} \cdot \mathrm{m}^{-2}$. It should be noted that any energy balance closure gap in the observed fluxes necessarily results in a bias in at least one of the simulated energy balance fluxes: $R_{\mathrm{n}}, G, H$ or $L E$, since the model forces energy balance closure. The quality of the reference measurements data set has been controlled by comparing the sum of convective fluxes $H+L E$ against the available
Table 2

Statistics of the comparison between the ground measured and the simulated energy fluxes obtained for each site. $\mu$ and $\sigma$ are the bias and the standard deviation of the differences between measurements and simulations. All data are in $\mathrm{W} \cdot \mathrm{m}^{-2}$.

\begin{tabular}{lllllll}
\hline Site & Flux & $\begin{array}{l}\mathrm{RMSE} \\
\left(\mathrm{W} \cdot \mathrm{m}^{-2}\right)\end{array}$ & $\begin{array}{l}\mu \\
\left(\mathrm{W} \cdot \mathrm{m}^{-2}\right)\end{array}$ & $\begin{array}{l}\sigma \\
\left(\mathrm{W} \cdot \mathrm{m}^{-2}\right)\end{array}$ & $R^{2}$ & $\begin{array}{l}\text { Number of } \\
\text { observations }\end{array}$ \\
\hline Avignon & $R_{\mathrm{n}}$ & 24 & -20 & 13 & 0.99 & 340 \\
& $L E$ & 31 & -15 & 27 & 0.95 & 262 \\
& $H$ & 37 & 18 & 33 & 0.65 & 301 \\
Bilos 2011 & $R_{\mathrm{n}}$ & 16 & 15 & 6 & 0.99 & 257 \\
& $L E$ & 35 & -2 & 35 & 0.69 & 253 \\
& $H$ & 42 & -14 & 40 & 0.81 & 258 \\
Bilos 2010 & $R_{\mathrm{n}}$ & 29 & 28 & 7 & 0.99 & 83 \\
& $L E$ & 29 & -3 & 29 & 0.55 & 61 \\
& $H$ & 66 & 51 & 42 & 0.62 & 83
\end{tabular}

energy $R_{\mathrm{n}}-G$. The agreement is quite good, with a RMSE of $\sim 50 \mathrm{~W} \cdot \mathrm{m}^{-2}$ for each site. This makes us very confident in the comparisons between simulated and measured fluxes. Similarly measured and simulated friction velocities were compared. The good agreement also found here (RMSE $<0.1 \mathrm{~m} \cdot \mathrm{s}^{-1}$ ) shows that the SCOPE computed aerodynamic resistance is not biased either, which reinforces the confidence one can have in simulated surface temperatures.

\subsection{Evaluation of surface temperature}

\subsubsection{Methodology}

In the standard version of SCOPE, the TOC emittances are computed by integrating the reflected diffuse radiations and the thermal emittances of all sunlit and shaded facets of all layers (vegetation and soil) which can be seen in a given viewing direction through a directional gap probability function. Although the transmittance of leaves in the thermal range is zero, obscured leaves that are not viewed directly still contribute indirectly by their influence on the diffuse fluxes in the canopy. The emitted flux of each layer in the observation direction depends on the probabilities that the element is (i) viewed, (ii) sunlit or (iii) both sunlit and viewed, leaf angle distribution function, extinction coefficients etc. (for more details, see the original paper e.g. Eqs.
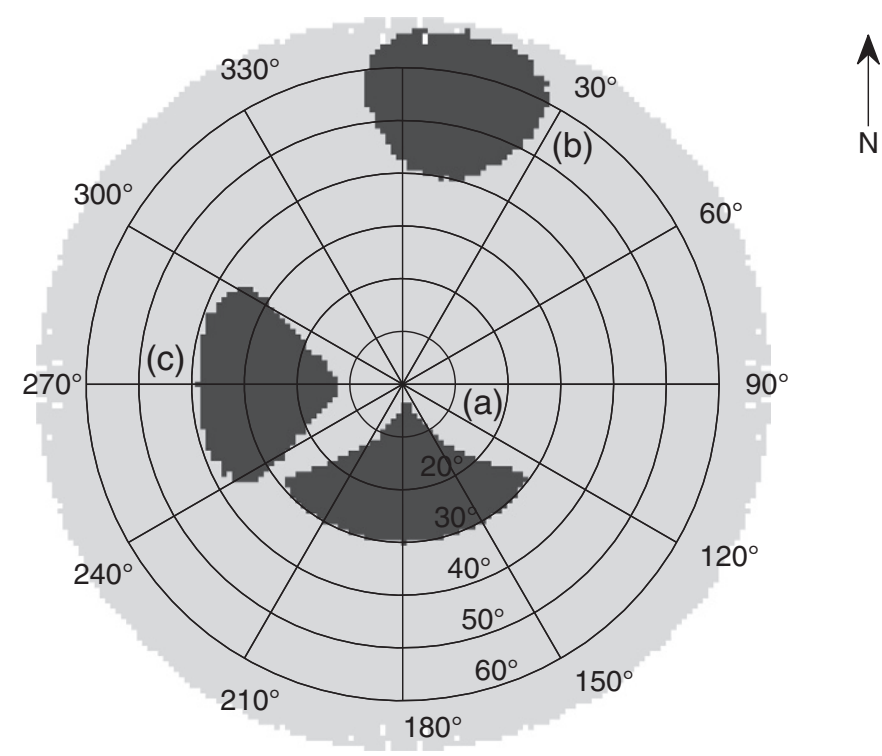

Fig. 4. Examples of directional configurations of the radiothermometers (semi-aperture angle of $14^{\circ}$ ). The radii correspond to the azimuthal viewing directions $\varphi_{v}$ and the concentric circles indicate the zenithal viewing angles $\theta_{\mathrm{v}}$. (a) $\theta_{\mathrm{v}}=18^{\circ} ; \phi_{\mathrm{v}}=180^{\circ}$; (b) $\theta_{\mathrm{v}}=55^{\circ} ; \phi_{\mathrm{v}}=10^{\circ}$; (c) $\theta_{\mathrm{v}}=27^{\circ} ; \phi_{\mathrm{v}}=270^{\circ}$. 

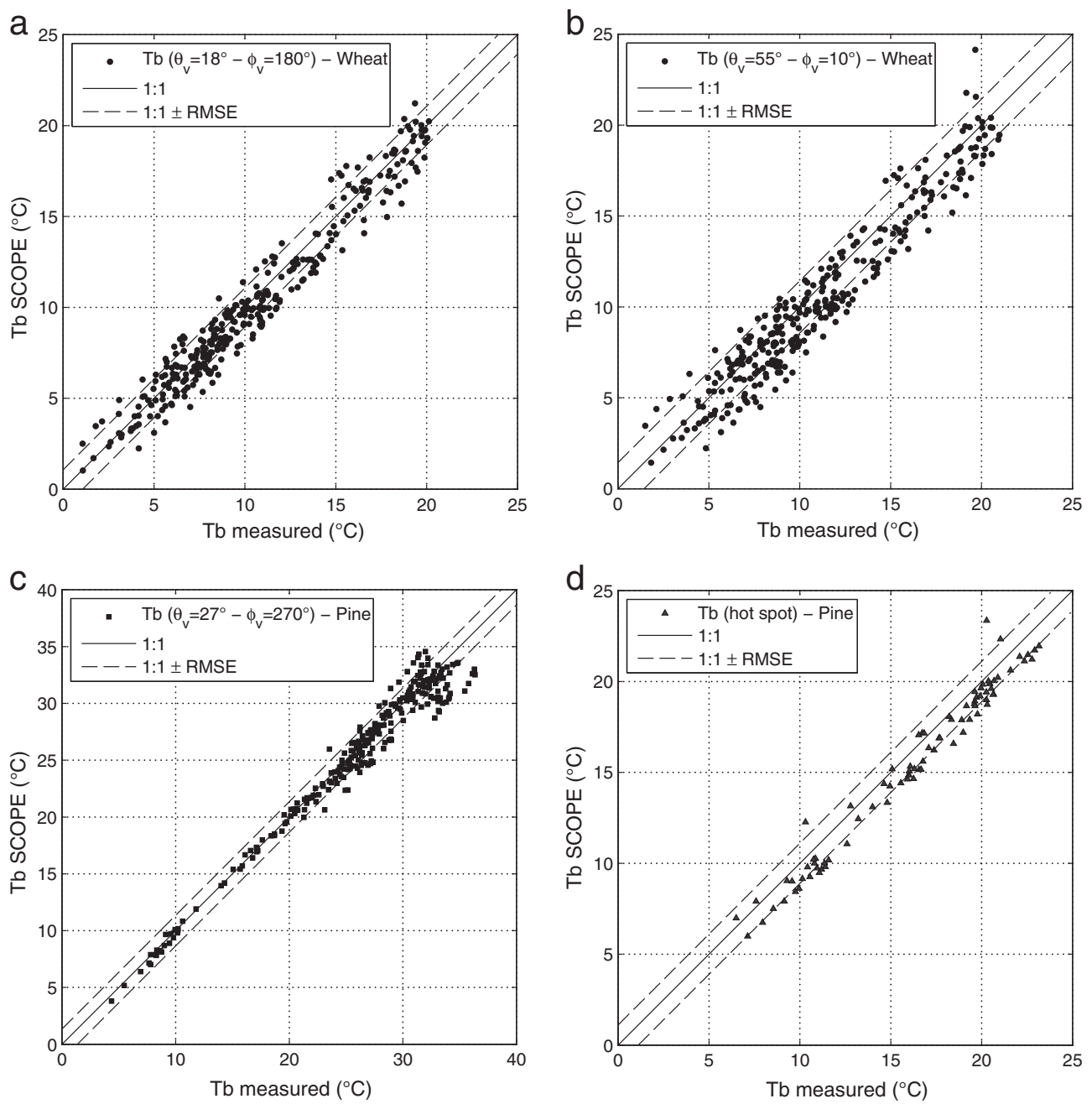

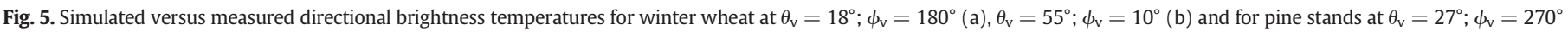
(c) and hot spot position (d). Squares and triangles (c and d) refer to 2010 and 2011 data respectively.

28-30). A brightness temperature $T_{\mathrm{STB}}\left(\theta_{\mathrm{v}}, \varphi_{\mathrm{v}}\right)$ is finally retrieved inverting the Stefan-Boltzmann law from the radiance ( $L$, units of $\mathrm{W} \mathrm{m}^{-2} \mathrm{sr}^{-1}$ ) in observation direction multiplied by $\pi(\mathrm{sr})$ :

$\pi L=\sigma T_{S T B}^{4}$

in which $\sigma$ is the Stefan Boltzmann constant $\left(5.67 \cdot 10^{-8} \mathrm{~W} \cdot \mathrm{m}^{-2} \cdot \mathrm{K}^{-4}\right)$.

5.2.1.1. Integration within the FOV of the radiometer. The measurements performed by the radiometer result from the integration of the directional temperatures in all the directions included within the FOV of the instrument. Fig. 4 illustrates the range of zenith and azimuth

Table 3

Statistics of the comparison between the ground measured and the simulated directional temperatures obtained for each site. $\mu$ and $\sigma$ are the bias and the standard deviation of the differences between measurements and simulations. All data are in ${ }^{\circ} \mathrm{C}$

\begin{tabular}{lllllll}
\hline Site & $\begin{array}{l}\text { Zenith } \\
\text { angle }\end{array}$ & RMSE $\left({ }^{\circ} \mathrm{C}\right)$ & $\mu\left({ }^{\circ} \mathrm{C}\right)$ & $\sigma\left({ }^{\circ} \mathrm{C}\right)$ & $R^{2}$ & $\begin{array}{l}\text { Number of } \\
\text { observations }\end{array}$ \\
\hline Avignon & $18^{\circ}$ & 1.1 & 0.3 & 1 & 0.95 & 324 \\
& $55^{\circ}$ & 1.4 & 0.7 & 1.3 & 0.93 & 323 \\
Bilos 2011 & $27^{\circ}$ & 1.3 & 0.4 & 1.3 & 0.97 & 265 \\
Bilos 2010 & Hot spot & 1.1 & 0.8 & 0.8 & 0.97 & 85 \\
\hline
\end{tabular}

viewing directions which had to be integrated for the different experimental setups over wheat and pine stands. We used a numerical integration over $N_{\mathrm{dir}}\left(\theta_{\mathrm{v}}, \varphi_{\mathrm{v}}\right)$ couples, chosen to cover the whole FOV. The integration was done according to the Stefan-Boltzmann law to derive a SCOPE temperature in the KT15 FOV as follows:

$T_{\text {SCO }, F O V}=\left[\frac{1}{N_{\text {dir }}} \sum_{\text {FOV }} T_{\text {STB }}^{4}\left(\theta_{v}, \varphi_{v}\right)\right]^{-4}$

Table 4

RMSE between the ground measured on wheat and the simulated latent and sensible heat fluxes for different couples of $V_{\mathrm{cmo}}$ and $\lambda$. Data for which RMSE is lower than a threshold of $50 \mathrm{~W} \cdot \mathrm{m}^{-2}$ are in bold.

\begin{tabular}{lllllll}
\hline RMSE $\left(\mathrm{W} / \mathrm{m}^{2}\right)$ & & \multicolumn{5}{l}{$V_{\mathrm{cmo}}\left(\mu \mathrm{mol} / \mathrm{m}^{2} / \mathrm{s}\right)$} \\
\cline { 3 - 6 } & & & 40 & 80 & 120 & 160 \\
\hline$\lambda(\mathrm{mol} / \mathrm{mol})$ & \multirow{2}{*}{500} & $L E$ & 154 & 123 & 100 & 83 \\
& & $H$ & 155 & 121 & 95 & 76 \\
& \multirow{2}{*}{2000} & $L E$ & 106 & 62 & $\mathbf{4 5}$ & $\mathbf{4 2}$ \\
& \multirow{2}{*}{4000} & $H$ & 100 & $\mathbf{4 8}$ & $\mathbf{2 8}$ & $\mathbf{2 8}$ \\
& & $L E$ & 76 & $\mathbf{4 5}$ & $\mathbf{5 3}$ & 63 \\
& & $H$ & 65 & $\mathbf{2 9}$ & $\mathbf{4 4}$ & 58 \\
& \multirow{2}{*}{6000} & $L E$ & 60 & $\mathbf{5 2}$ & 71 & 84 \\
& $H$ & $\mathbf{4 4}$ & $\mathbf{4 2}$ & 66 & 80 \\
\hline
\end{tabular}


Table 5

Bias of the difference between the ground measured on wheat and the simulated latent and sensible heat fluxes for different couples of $V_{\mathrm{cmo}}$ and $\lambda$. Data for which bias is lower than a threshold of $50 \mathrm{~W} \cdot \mathrm{m}^{-2}$ are in bold.

\begin{tabular}{|c|c|c|c|c|c|c|}
\hline \multirow[t]{2}{*}{$\operatorname{Bias}\left(\mathrm{W} / \mathrm{m}^{2}\right)$} & & & \multicolumn{4}{|c|}{$V_{\mathrm{cmo}}\left(\mu \mathrm{mol} / \mathrm{m}^{2} / \mathrm{s}\right)$} \\
\hline & & & 40 & 80 & 120 & 160 \\
\hline \multirow[t]{8}{*}{$\lambda(\mathrm{mol} / \mathrm{mol})$} & 500 & $L E$ & 133 & 105 & 83 & 68 \\
\hline & & $H$ & -130 & -101 & -79 & -62 \\
\hline & 2000 & $L E$ & 91 & 45 & 17 & 1 \\
\hline & & $H$ & -85 & -37 & -9 & 7 \\
\hline & 4000 & $L E$ & 61 & 8 & -20 & -36 \\
\hline & & $H$ & -53 & 1 & 27 & 42 \\
\hline & 6000 & $L E$ & 41 & -15 & -43 & -58 \\
\hline & & $H$ & -32 & 23 & 49 & 62 \\
\hline
\end{tabular}

$N_{\text {dir }}$ being the number of $\left(\theta_{\mathrm{v}}, \varphi_{\mathrm{v}}\right)$ couples seen within the FOV. Strictly, the weighting should be made according to the surfaces seen at ground in any $\left(\theta_{\mathrm{v}}, \varphi_{\mathrm{v}}\right)$ direction, to take into account the variation of elementary surfaces with zenith angle. This has only very little impact here.

\subsubsection{Results}

The comparisons between SCOPE simulated and measured directional temperatures are given in Fig. 5 with the statistics in Table 3. The agreement is very good for both surfaces and whatever the viewing configurations, with $R^{2}$ correlation coefficients always above 0.93 .

For wheat, the RMSE are $1.1 \mathrm{~K}$ and $1.4 \mathrm{~K}$ for the two setups (pointing South and pointing North), with low bias.

For the 2011 pine experiment the RMSE is quite similar, with an excellent agreement up to $25^{\circ} \mathrm{C}$ and some scatter around the $1: 1$ line beyond. As the LAI had not been measured accurately in this case, we repeated the simulations with a $\pm 20 \%$ variation around its nominal value first considered. This only led to a small degradation of 0.1 (for $\mathrm{LAI}=1.2$ ) and 0.3 (for $\mathrm{LAI}=1.8$ ) on the RMSE, and an increase of the bias from 0.4 to $1.1 \mathrm{~K}$ when using a 1.8 value for LAI instead of the 1.5 nominal one.

For the 2010 pine measurements performed in hot spot viewing direction, we obtained RMSE of $1.1{ }^{\circ} \mathrm{C}$ with a systematic bias of $0.8^{\circ} \mathrm{C}$. As an impact of the hot spot parameterization could be expected on these simulations, we tested a $\pm 40 \%$ variation on the $w$ parameter related to the size of shoots. RMSE varies from $1.7^{\circ} \mathrm{C}$ at worst when $w / h c$ is 0.008 (corresponding to $w=2 \mathrm{~cm}$ ) to $0.8{ }^{\circ} \mathrm{C}$ at best when $w / h c$ is 0.08 . The difference between both is small, because of the integration of the temperatures in the FOV of the instrument. It should be noted that $w$ only affects the size of the hotspot, and with any realistic value of $w$, the hotspot is smaller than the FOV of the instrument. This parameter will be discussed in Section 6 .

\subsubsection{Sensitivity to $V_{\text {cmo }}$ and $\lambda$ parameters}

As $V_{\mathrm{cmo}}$ and $\lambda$ are difficult to obtain, either because of scarcity of literature references, or because their calibration requires measurements

\section{Table 6}

Idem than Table 4 but considering directional temperatures at $\theta_{\mathrm{v}}=18^{\circ} ; \varphi_{\mathrm{v}}=180^{\circ}\left(\mathrm{Tb} 18^{\circ}\right)$, $\theta_{\mathrm{v}}=55^{\circ} ; \varphi_{\mathrm{v}}=10^{\circ}\left(\mathrm{Tb} 55^{\circ}\right)$.

\begin{tabular}{|c|c|c|c|c|c|c|}
\hline \multirow[t]{2}{*}{$\operatorname{RMSE}\left({ }^{\circ} \mathrm{C}\right)$} & & & \multicolumn{4}{|c|}{$V_{\mathrm{cmo}}\left(\mu \mathrm{mol} / \mathrm{m}^{2} / \mathrm{s}\right)$} \\
\hline & & & 40 & 80 & 120 & 160 \\
\hline \multirow[t]{8}{*}{$\lambda(\mathrm{mol} / \mathrm{mol})$} & 500 & $\operatorname{Tb} 18^{\circ}$ & 1.07 & 1.04 & 1.03 & 1.03 \\
\hline & & $\mathrm{Tb} 55^{\circ}$ & 1.29 & 1.22 & 1.21 & 1.22 \\
\hline & 2000 & $\mathrm{~Tb} 18^{\circ}$ & 1.03 & 1.04 & 1.08 & 1.11 \\
\hline & & $\operatorname{Tb} 55^{\circ}$ & 1.20 & 1.23 & 1.34 & 1.42 \\
\hline & 4000 & $\operatorname{Tb} 18^{\circ}$ & 1.02 & 1.09 & 1.14 & 1.18 \\
\hline & & $\mathrm{Tb} 55^{\circ}$ & 1.19 & 1.34 & 1.48 & 1.62 \\
\hline & 6000 & $\operatorname{Tb} 18^{\circ}$ & 1.04 & 1.12 & 1.18 & 1.26 \\
\hline & & $\mathrm{Tb} 55^{\circ}$ & 1.29 & 1.41 & 1.60 & 1.82 \\
\hline
\end{tabular}

Table 7

Idem than Table 5 but considering directional temperatures at $\theta_{\mathrm{v}}=18^{\circ} ; \varphi_{\mathrm{v}}=180^{\circ}\left(\mathrm{Tb} 18^{\circ}\right)$ $\theta_{\mathrm{v}}=55^{\circ} ; \varphi_{\mathrm{v}}=10^{\circ}\left(\mathrm{Tb} 55^{\circ}\right)$.

\begin{tabular}{|c|c|c|c|c|c|c|}
\hline \multirow[t]{2}{*}{$\operatorname{Bias}\left({ }^{\circ} \mathrm{C}\right)$} & & & \multicolumn{4}{|c|}{$V_{\mathrm{cmo}}\left(\mu \mathrm{mol} / \mathrm{m}^{2} / \mathrm{s}\right)$} \\
\hline & & & 40 & 80 & 120 & 160 \\
\hline \multirow{8}{*}{$\lambda(\mathrm{mol} / \mathrm{mol})$} & 500 & $\mathrm{~Tb} 18^{\circ}$ & -0.31 & -0.16 & -0.06 & 0.01 \\
\hline & & $\operatorname{Tb} 55^{\circ}$ & -0.35 & -0.13 & 0.05 & 0.18 \\
\hline & 2000 & $\operatorname{Tb} 18^{\circ}$ & -0.11 & 0.13 & 0.26 & 0.34 \\
\hline & & $\mathrm{Tb} 55^{\circ}$ & -0.06 & 0.30 & 0.53 & 0.69 \\
\hline & 4000 & $\operatorname{Tb} 18^{\circ}$ & 0.04 & 0.31 & 0.44 & 0.50 \\
\hline & & $\mathrm{Tb} 55^{\circ}$ & 0.14 & 0.55 & 0.79 & 0.90 \\
\hline & 6000 & $\operatorname{Tb} 18^{\circ}$ & 0.13 & 0.42 & 0.51 & 0.54 \\
\hline & & $\mathrm{Tb} 55^{\circ}$ & 0.23 & 0.70 & 0.87 & 0.95 \\
\hline
\end{tabular}

not always available (in our case we used actual evapotranspiration and $\mathrm{CO}_{2}$ assimilation), we evaluated their influence on the SCOPE simulation results and the impact of prescribing a priori constant values for both of them. The exercise was performed on the wheat experiment. Considering the mean values (approximately $120 \mu \mathrm{mol} \cdot \mathrm{m}^{-2} \cdot \mathrm{s}^{-1}$ and
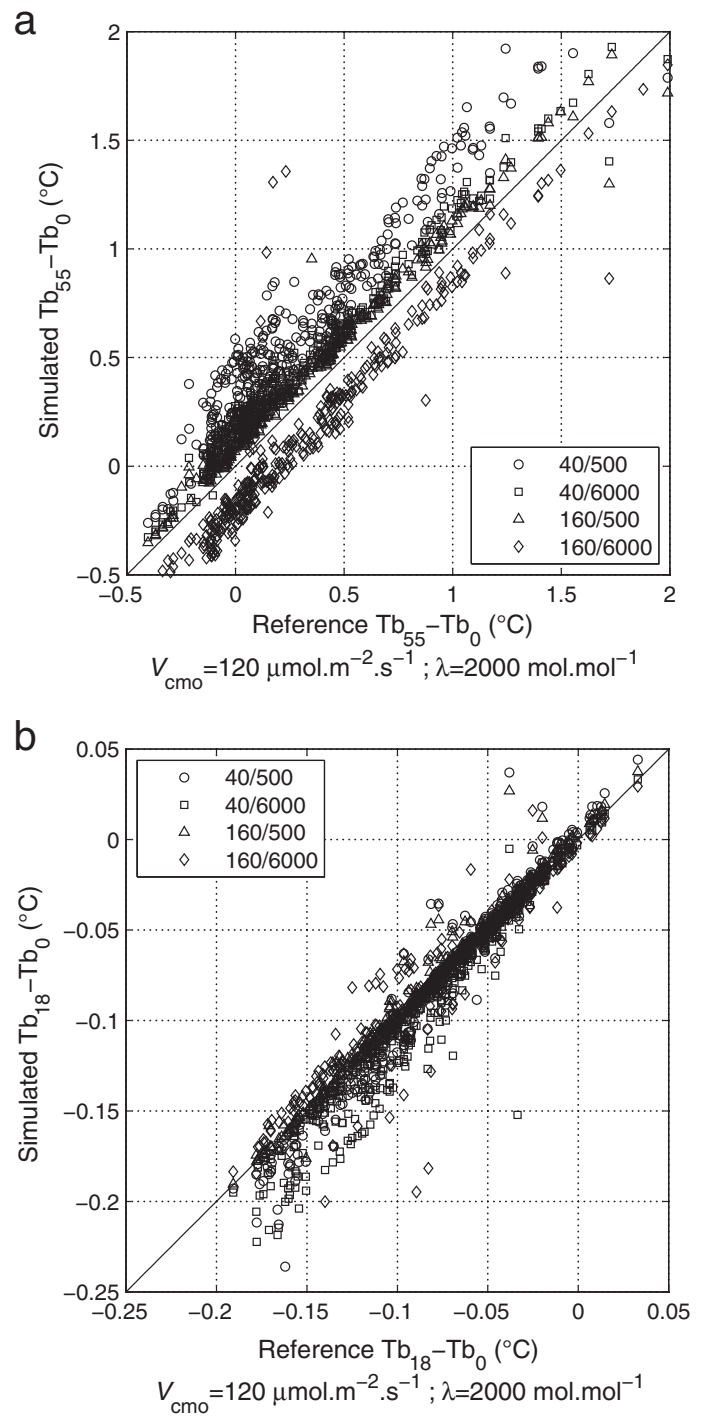

Fig. 6. $\mathrm{Tb}_{55}-\mathrm{Tb}_{0}$ (a) and $\mathrm{Tb}_{18}-\mathrm{Tb}_{0}$ (b) simulated with 4 couples of $V_{\mathrm{cmo}}$ and $\lambda$ (circles for $V_{\mathrm{cmo}}=40 \mu \mathrm{mol} \cdot \mathrm{m}^{-2} \cdot \mathrm{s}^{-1} / \lambda=500 \mathrm{~mol} \cdot \mathrm{mol}^{-1}$; squares for $V_{\mathrm{cmo}}=40 \mu \mathrm{mol} \cdot \mathrm{m}^{-2} \cdot \mathrm{s}^{-1}$ $\lambda=6000 \mathrm{~mol} \cdot \mathrm{mol}^{-1}$; triangles for $V_{\mathrm{cmo}}=160 \mu \mathrm{mol} \cdot \mathrm{m}^{-2} \cdot \mathrm{s}^{-1} / \lambda=500 \mathrm{~mol} \cdot \mathrm{mol}^{-1}$ and diamonds for $V_{\mathrm{cmo}}=160 \mu \mathrm{mol} \cdot \mathrm{m}^{-2} \cdot \mathrm{s}^{-1} / \lambda=6000 \mathrm{~mol} \cdot \mathrm{mol}^{-1}$ ) versus respective anisotropy obtained with the couple $V_{\mathrm{cmo}}=120 \mu \mathrm{mol} \cdot \mathrm{m}^{-2} \cdot \mathrm{s}^{-1}$ and $\lambda=2000 \mathrm{~mol} \cdot \mathrm{mol}^{-1}$. 
$4000 \mathrm{~mol} \cdot \mathrm{mol}^{-1}$ ) and the dispersion obtained on the retrieved calibrated values, $V_{\mathrm{cmo}}$ was varied between 40 and $160 \mu \mathrm{mol} \cdot \mathrm{m}^{-2} \cdot \mathrm{s}^{-1}$ by $40 \mu \mathrm{mol} \cdot \mathrm{m}^{-2} \cdot \mathrm{s}^{-1}$ steps, and $\lambda$ between 500 and $6000 \mathrm{~mol} \cdot \mathrm{mol}^{-1}$. For each of the 16 simulations run, the $H$ and $L E$ fluxes, and the directional temperatures in the two viewing directions $\mathrm{Tb}_{18}\left(18^{\circ}\right.$ zenith, $270^{\circ}$ azimuth) and $\mathrm{Tb}_{55}\left(55^{\circ}\right.$ zenith, $10^{\circ}$ azimuth) were compared against the measurements. The RMSE and bias are given in Tables 4-7. In Tables 4 and 5, fluxes meeting the quality criteria RMSE $<50 \mathrm{~W} \mathrm{~m}^{-2}$

a

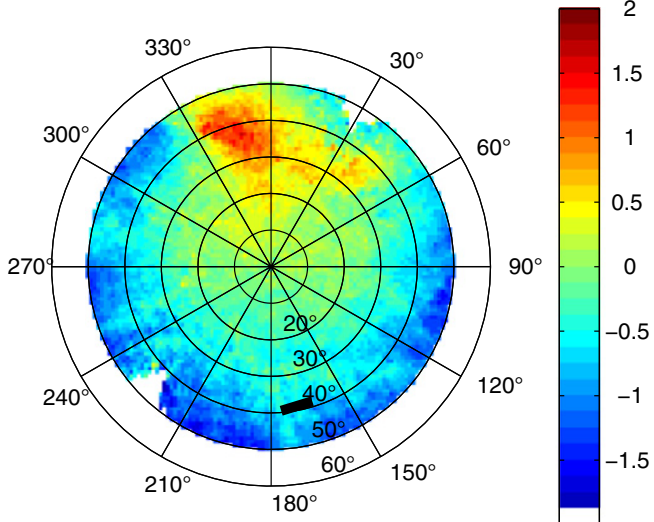

C

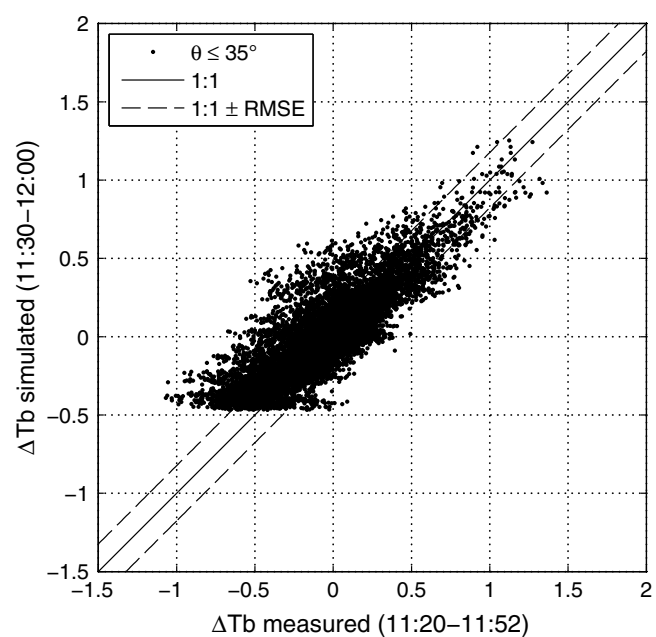

e

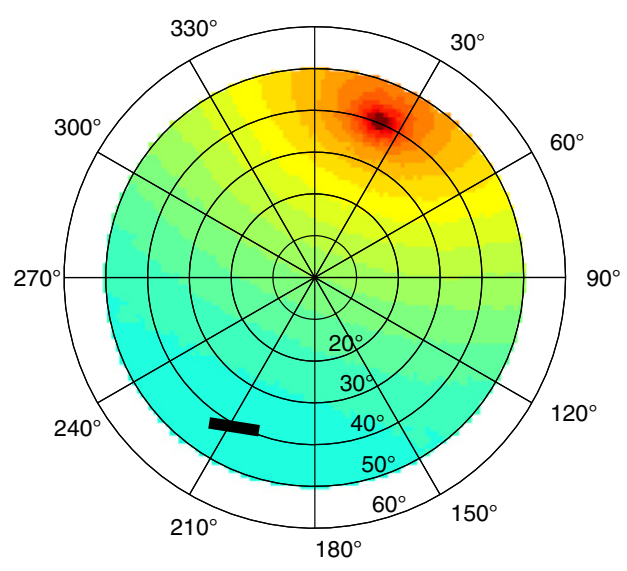

and bias $<50 \mathrm{~W} \mathrm{~m}^{-2}$, consistent with the calibration exercise results, are identified in bold. It is evident that only a limited number of combinations of $V_{\mathrm{cmo}}$ and $\lambda$ result in accurate output of the fluxes, and that the quality of the simulated fluxes degraded rapidly as the values of the two parameters deviate from the optimum values.

The surface temperature appears to be less sensitive to $V_{\mathrm{cmo}}$ and $\lambda$ than the fluxes, with RMSE values of both $\mathrm{Tb}_{18}$ and $\mathrm{Tb}_{55}$ most of the $\mathrm{b}$

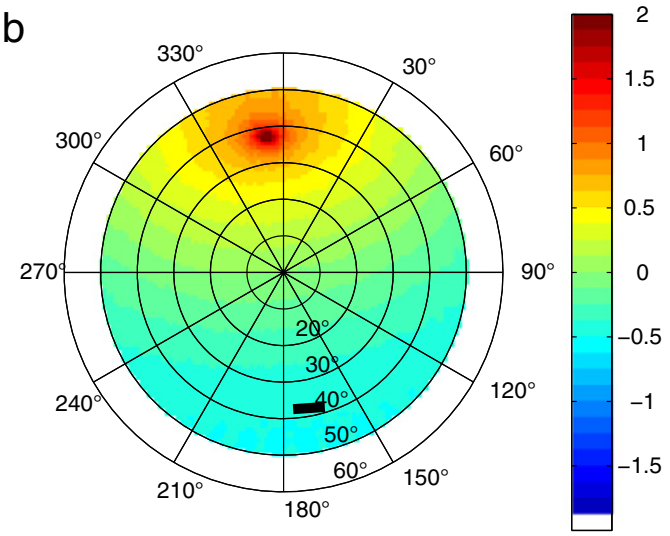

d

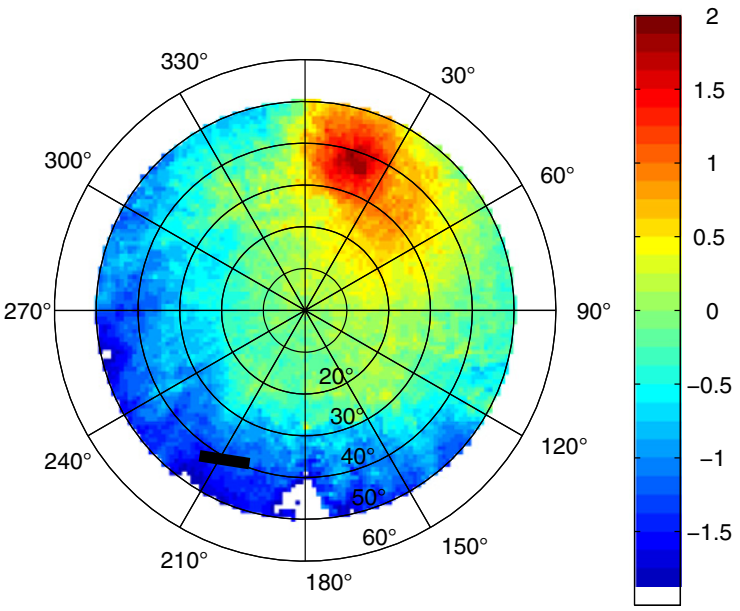

$f$

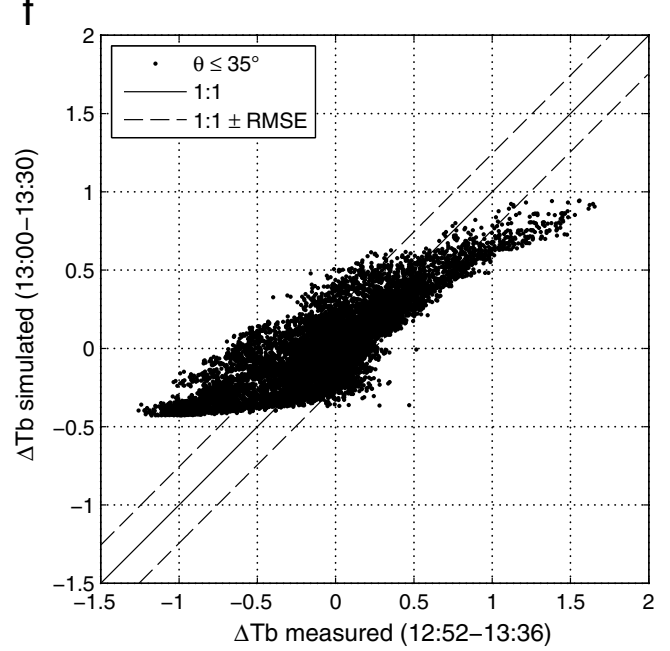

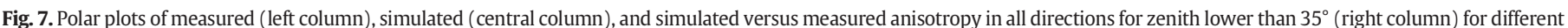

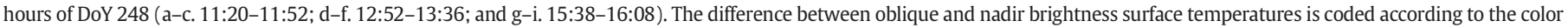
bars associated with each polar plot. The black line indicates the sun course during the period of measurements. 

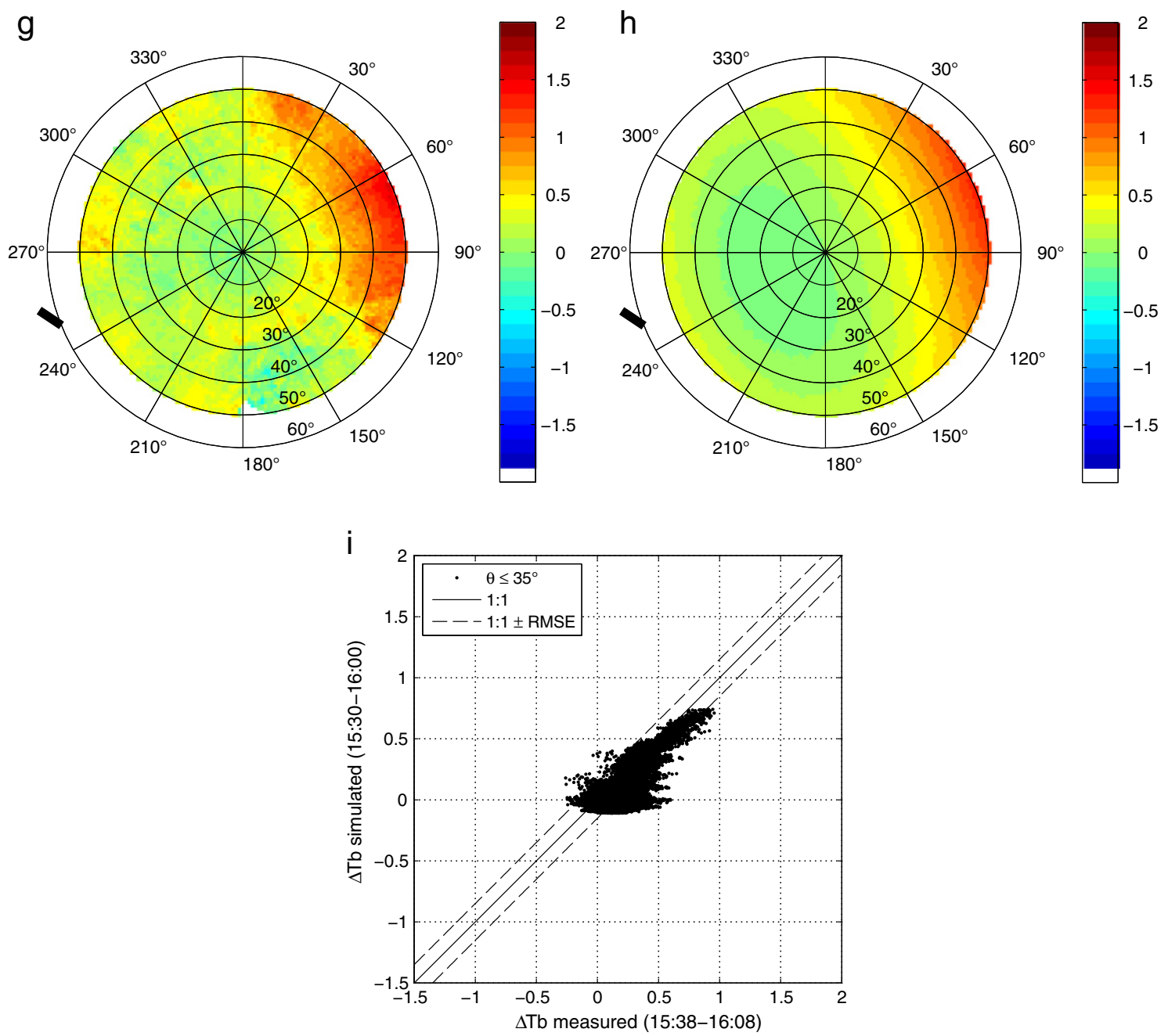

Fig. 7 (continued).

time comprised between $1.0{ }^{\circ} \mathrm{C}$ and $1.5{ }^{\circ} \mathrm{C}$, which is consistent with the $1.1{ }^{\circ} \mathrm{C}$ and $1.4{ }^{\circ} \mathrm{C}$ found for the calibrated $\mathrm{Tb}_{18}$ and $\mathrm{Tb}_{55}$. The bias keeps acceptable values, lower than about $0.7{ }^{\circ} \mathrm{C}$ in absolute value, except for both high $V_{\text {cmo }}$ and $\lambda$. For the $V_{\text {cmo }}$ and $\lambda$ sets, we considered providing acceptable values of temperatures, the bias ranges between $0.1^{\circ} \mathrm{C}$ and $0.4{ }^{\circ} \mathrm{C}$ for $\mathrm{Tb}_{18}$, and between $0.2{ }^{\circ} \mathrm{C}$ and $0.7{ }^{\circ} \mathrm{C}$ for $\mathrm{Tb}_{55}$. We also notice that the biases of $\mathrm{Tb}_{18}$ and $\mathrm{Tb}_{55}$ generally have the same sign. This means that they are similarly affected by uncertainties on $V_{\mathrm{cmo}}$ and $\lambda$, with consequently less impact on directional anisotropy. Contrary to flux estimation purposes which require careful calibration of the model, this indicates that SCOPE can potentially be used with realistic prescribed $V_{\text {cmo }}$ and $\lambda$ parameters for surface temperature directional anisotropy simulation.

This is confirmed in Fig. 6 where the anisotropy $\mathrm{Tb}_{18}-\mathrm{Tb}_{0}\left(\mathrm{~Tb}_{0}\right.$ corresponds to surface temperature simulated at nadir) and $\mathrm{Tb}_{55}-\mathrm{Tb}_{0}$ simulated for the $16\left(V_{\mathrm{cmo}}, \lambda\right)$ sets were plotted against the corresponding values obtained with $V_{\text {cmo }}=120 \mu \mathrm{mol} \cdot \mathrm{m}^{-2} \mathrm{~s}^{-1}$ and $\lambda=2000 \mathrm{~mol} \cdot \mathrm{mol}^{-1}$ resulting from the calibration exercise and considered to be a reference. The small scatter around the 1:1 line with limited scatter clearly illustrates the low sensitivity of anisotropy to $V_{\mathrm{cmo}}$ and $\lambda$. When aiming North (Fig. 6a) the anisotropy is larger than when aiming South (Fig. 6b) for several reasons: (i) more sunlit vegetation facets seen when the canopy is observed with the Sun in the back, (ii) $18^{\circ}$ zenithal viewing angle close to nadir, and (iii) in directions opposite to Sun where most facets are shaded. The vegetation water status also drives the anisotropy, which explains the sensitivity to $V_{\mathrm{cmo}}$ in Fig. 6b: when well watered $\left(V_{\mathrm{cmo}}=160 \mu \mathrm{mol} \cdot \mathrm{m}^{-2} \cdot \mathrm{s}^{-1}\right)$, the temperature of the vegetation facets display lower temperatures and less scatter, contrarily to drier conditions $\left(V_{\mathrm{cmo}}=40 \mu \mathrm{mol} \cdot \mathrm{m}^{-2} \cdot \mathrm{s}^{-1}\right)$

The relatively low sensitivity of surface temperature and surface temperature anisotropy to the parameters $V_{\mathrm{cmo}}$ and $\lambda$ around realistic values also suggests that they may not be good indicators of the water and carbon dioxide fluxes directly.

\section{Application to the simulation of TIR angular anisotropy}

The first part of the study demonstrated the ability of SCOPE to simulate energy fluxes and FOV integrated directional temperatures. The simulation of the directional anisotropy appeared to be little influenced by the uncertainties in the calibrated parameters. We now present a simulation exercise devoted to illustrate the capacity of SCOPE to simulate anisotropy of LST in a large range of viewing directions by a qualitative comparison against airborne measurements performed over the mature maritime pine stand of Le Bray described in Section 3.3.

Three comparisons were made at different times of the day, on September 4th, 1996. To match the different flight times (11:20-11:52, 12:52-13:36 and 15:38-16:08 UTC) as close as possible, SCOPE was run on 30 min time steps over the periods 11:30-12:00, 13:00-13:30 and 15:30-16:00 UTC. The anisotropy was simulated by $1^{\circ}$ steps in all azimuth directions and for zenith viewing angles up to $50^{\circ}$. The model was run with $V_{\mathrm{cmo}}=50 \mu \mathrm{mol} \cdot \mathrm{m}^{-2} \mathrm{~s}^{-1}$ and $\lambda=2000 \mathrm{~mol} \cdot \mathrm{mol}^{-1}$. The hot spot 
parameter $l$ was given the value 0.034 , which corresponds to a leaf or shoot width $w=60 \mathrm{~cm}$ for a tree height $h_{\mathrm{c}}=17.6 \mathrm{~m}$.

Fig. 7 clearly shows that measured and simulated directional LST anisotropy display the same patterns and similar ranges of magnitude for the 3 flights. The hot spot shape and its position changes throughout the day are correctly reproduced. For the first 2 flights we can observe some discrepancies of about $1{ }^{\circ} \mathrm{C}$ for zenith viewing angles larger than 30 or $40^{\circ}$ in the direction opposite to hot spot. Nevertheless if we consider the $35^{\circ}$ limit scan angle specified for the THIRSTY mission, the agreement remains excellent as shown on the plots presented in Fig. 7.c., 7.f and 7.i. (RMSE $\sim 0.2{ }^{\circ} \mathrm{C}$, bias $\sim 0.05^{\circ} \mathrm{C}$ ).

These results confirm the potential of SCOPE as a tool for simulating and studying the TIR directional anisotropy and are very promising. A detailed validation nevertheless remains to be done, and attention must be drawn on several points:

- The canopy structure on the mature pine stand somewhat differs from the model assumptions, as it displays two distinct layers, one for crowns, the other for the understory, with only trunks with no LAI in between.

- The measured anisotropy using an airborne camera is likely to be 'angular-smoothed' because of the combined effects (i) of the rapid variations in the attitude of the aircraft with turbulence (pitch, roll and yaw angles), (ii) of the fluctuations of surface temperature induced by those of wind speed (Lagouarde et al., 2013b), and (iii) of the Sun displacement during the flights.

- On the SCOPE model side, attention is to be paid to the hot spot parameterization which governs both its width shape (angular dependence) and intensity. The sensitivity of the anisotropy (difference between temperature at hot spot and nadir) in the principal solar plane for different assumptions of shoot widths $w$ has been tested on simulations performed at 12:00 and 13:30. The results are quite similar. In Fig. 8 the anisotropy is plotted against the zenith viewing angle for the 12:00 case only. Each curve is the average of several ones (in a range of about $\pm 3^{\circ}$ ) around the mean Sun azimuth, in order to account for variations in the azimuth variation during the flight. The simulation with $w=60 \mathrm{~cm}$ fits the measured anisotropy best. The anisotropy at hot spot increases when $w$ increases. We have limited confidence in the measured anisotropy close to hot spot due to the earlier mentioned smoothing effects that may lead to a wider (in terms of angles) but less intense (in terms of the peak temperature) hotspot than in reality. This uncertainty limits the evaluation of the parameter $w$ at present. We therefore recommend future experiments to include ground measurements using adapted setups (fixed instruments mounted on masts for instance) to eliminate perturbations of airborne data, with the scope of assessing the hot spot shape in more detail, for a thorough validation of the $w / h_{c}$ effect in SCOPE.

\section{Conclusion}

This paper focused on the evaluation of the SCOPE model in the thermal infrared. The SVAT SCOPE model (Van der Tol et al., 2009) has been developed to simulate both fluxes (energy, water, and $\mathrm{CO}_{2}$ ) and remote sensing signatures in the $0.4-50 \mu \mathrm{m}$ domain. The context of our study is in fact much wider, and deals with the development of simple TIR directional anisotropy models robust enough to be implemented in future routine satellite data processing tools devoted to the production of levels 2 or 3 elaborated data. Large amounts of directional TIR data are required to calibrate and validate new methodologies in a wide range of conditions. Such data not being available experimentally or difficult to measure, SCOPE here appears very attractive as it could be used as a data generator.

Two datasets of field measurements over a winter wheat crop and a young pine stand were used to calibrate and validate the model. These data sets included measurements of energy, water and CO2 fluxes, and measurements of directional brightness temperatures using TIR radiometers in different viewing configurations. In the calibration phase, two vegetation biological parameters less frequently documented in literature, the maximal carboxylation capacity $\left(V_{\mathrm{cmo}}\right)$ and the marginal cost of assimilation $(\lambda)$, were adjusted by fitting the simulated and measured latent heat flux and net $\mathrm{CO}_{2}$ assimilation. The values of $V_{\mathrm{cmo}}$ and $\lambda$ found are consistent with data previously reported, but they display important temporal variations at daily scale which could result either from insufficient description of the processes involved (possible effects of temperature or soil moisture on $V_{\mathrm{cmo}}$ and $\lambda$ as mentioned by Medlyn et al. (2002) and Wilson et al. (2000) for instance) or numerical uncertainties. The validation of SCOPE was performed in a second step for surface temperatures. The results are quite satisfactory with RMSE of about $30-40 \mathrm{~W} \cdot \mathrm{m}^{-2}$ for fluxes and RMSE always better than $1.4 \mathrm{~K}$ for the 4 different viewing configurations investigated, with very low bias for surface temperatures. A brief sensitivity study revealed that the simulated temperatures and directional anisotropy were less affected by uncertainties on $V_{\mathrm{cmo}}$ and $\lambda$ than sensible and latent heat fluxes. This is an important result as our purpose is to use SCOPE as a data generator of anisotropy.

The difficulty to obtain accurate values for $V_{\mathrm{cmo}}$ and $\lambda$ (or comparable photosynthetic and stomatal parameters) is not likely to be resolved soon, at least not by using thermal remote sensing observations. Nevertheless, we consider laboratory or controlled field experiments of thermal anisotropy as a useful direction to obtain better understanding of the hot spot dependence on canopy structure.

The potential of SCOPE as a tool for simulating the TIR directional anisotropy was finally illustrated by a comparison against an available dataset collected over a mature maritime pine stand in 1996 September the 4th (Lagouarde et al., 2000) using an airborne TIR camera. Although the structure of the stand, which displays 2 separated layers of understory vegetation and tree crowns, somewhat deviates from the assumptions of a homogeneous media made in SCOPE, the simulation of anisotropy at 3 different times in the day and for a large range of viewing directions (up to $50^{\circ}$ zenith angles and in all azimuth directions) revealed to be excellent. Both the variations of position of the hot spot throughout the day (from 11:20 am to 4:00 pm UTC) and the range of anisotropy values agreed very well. In particular if we limit the comparison for zenith viewing angles lower than $35^{\circ}$, which corresponds to the maximum scan angle accepted for the THIRSTY mission, the agreement between SCOPE simulated and measured directional anisotropy is already quite satisfactory with a RMSE close to $0.2{ }^{\circ} \mathrm{C}$ and no bias.

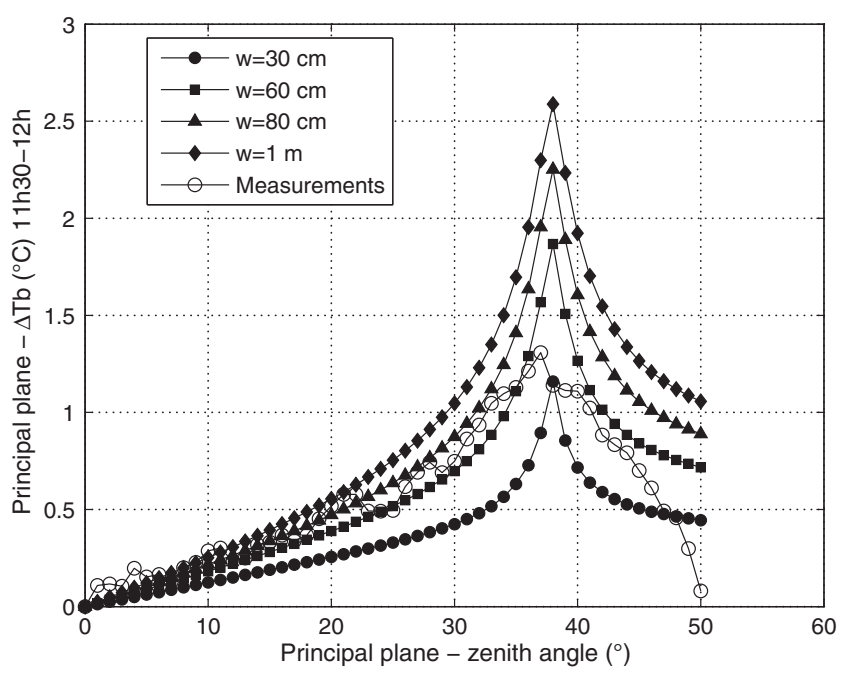

Fig. 8. Anisotropy in principal plane versus zenith angle for different realistic shoot widths for the period 11:30 - 12:00 UTC. Circles correspond to $w / h_{\mathrm{c}}=0.017$, squares represent $w / h_{c}=0.034$, triangles stand for $w / h_{c}=0.045$ and diamonds display $w / h_{c}=0.57$. The anisotropy was averaged on the range of azimuths of the sun during the period. 
Even if important improvements are to be expected from better assessment of the $w$ parameter for the hot spot shape, and possibly, to a lesser degree, of the critical $V_{\mathrm{cmo}}$ and $\lambda$ parameters for vegetation resistance, and additional validation needed, SCOPE in its present status appears from now on as an excellent deterministic tool to simulate both surface fluxes and directional temperatures. Making possible detailed sensitivity studies or contributing to the development of simplified methods for assessing directional effects, in particular using it as a data generator, it should significantly help in the interpretation of satellite data from future TIR mission.

\section{Acknowledgments}

This work was supported by the 'Centre National d'Etudes Spatiales' (CNES) through the TOSCA (Terre, Océan, Surfaces Continentales, Atmosphère) group and the 'Institut National de la Recherche Agronomique' (INRA), Department of 'Environnement et Agronomie'. The authors would like to thank Christophe Chipeaux (INRA ISPA, Bordeaux) and Olivier Marloie and Sébastien Garrigues (INRA EMMAH laboratory, Avignon) who provided the data.

\section{References}

Abrams, M.J., \& Hook, S.J. (2013). NASA's hyperspectral infrared imager (HyspIRI). In C. Kuenzer, \& S. Dech (Eds.), Thermal infrared remote sensing (pp. 117-130). Netherlands: Springer.

Aubinet, M., et al. (2000). Estimates of the annual net carbon and water exchange of forests: The EUROFLUX methodology. Advances in Ecological Research, 30, 113-175. http://dx.doi.org/10.1016/s0065-2504(08)60018-5.

Balick, L., \& Hutchinson, B. (1986). Directional thermal infrared exitance distributions from a leafless deciduous forest. IEEE Transactions on Geoscience and Remote Sensing, GE-24, 693-698. http://dx.doi.org/10.1109/TGRS.1986.289616.

Berbigier, P., \& Bonnefond, J. (1995). Measurement and modelling of radiation transmission within a stand of maritime pine (Pinus pinaster Ait). Annals of Forest Science, 52, 23-42. http://dx.doi.org/10.1051/forest:19950103.

Berk, A., Anderson, G., Acharya, P., Chetwynd, J.H., Bern-stein, L.S., Shettle, E.P., et al. (1999). MODTRAN4 user's manual. Air Force Research Laboratory's Space Vehicles Directorate Air Force Master Command, 99.

Bhumralkar, C.M. (1975). Numerical experiments on the computation of ground surface temperature in an atmospheric general circulation model. Journal of Applied Meteorology, 14, 1246-1258. http://dx.doi.org/10.1175/1520-0450(1975)014<1246: NEOTCO $>2.0 . C O ; 2$

Bunce, J.A. (2000). Acclimation of photosynthesis to temperature in eight cool and warm climate herbaceous $C(3)$ species: Temperature dependence of parameters of a biochemical photosynthesis model. Photosynthesis Research, 63, 59-67. http://dx doi.org/10.1023/A:1006325724086.

Caselles, V., \& Sobrino, J. (1989). Determination of frosts in orange groves from NOAA-9 AVHRR data. Remote Sensing of Environment, 29, 135-146. http://dx.doi.org/10. 1016/0034-4257(89)90022-9.

Cowan, I. (1977). Stomatal behaviour and environment. Advances in Botanical Research, 4 $117-228$.

Crebassol, P., et al. (2014). THIRSTY Thermal InfraRed SpaTial System. In 2014 IEEE Geoscience and Remote Sensing Symposium (pp. 3021-3024). http://dx.doi.org/10.1109/ IGARSS.2014.6947113.

Denis, D. (2013). Irrigation performance assessment using SEBS and SCOPE. A case study of Tons pump Canal Command in India.

Dornbusch, T., Watt, J., Baccar, R., Fournier, C., \& Andrieu, B. (2011). A comparative analysis of leaf shape of wheat, barley and maize using an empirical shape model. Annals of Botany, 107, 865-873. http://dx.doi.org/10.1093/aob/mcq181.

Farquhar, G.D., von Caemmerer, S., \& Berry, J.A. (1980). A biochemical model of photosynthetic $\mathrm{CO}_{2}$ assimilation in leaves of $\mathrm{C}_{3}$ species. Planta, 149, 78-90. http://dx.doi.org/10. 1007/BF00386231.

Fuchs, M., \& Kanemasu, E. (1967). Effect of viewing angle on canopy temperature measurements with infrared thermometers. Agronomy Journal, 59, 494-496.

Fuchs, M., \& Tanner, C. (1966). Infrared thermometry of vegetation. Agronomy Journal, 58, 597-601.

Gerber, F., Marion, R., Olioso, a., Jacquemoud, S., Ribeiro da Luz, B., \& Fabre, S. (2011). Modeling directional-hemispherical reflectance and transmittance of fresh and dry leaves from $0.4 \mu \mathrm{m}$ to $5.7 \mu \mathrm{m}$ with the PROSPECT-VISIR model. Remote Sensing of Environment, 115, 404-414. http://dx.doi.org/10.1016/j.rse.2010.09.011.

Grossman-Clarke, S., et al. (1999). Effects of elevated atmospheric $\mathrm{CO}_{2}$ on canopy transpiration in senescent spring wheat. Agricultural and Forest Meteorology, 93, 95-109. http://dx.doi.org/10.1016/S0168-1923(98)00111-7.

Guillevic, P. (2003). Thermal infrared radiative transfer within three-dimensional vegetation covers. Journal of Geophysical Research, 108, 4248. http://dx.doi.org/10.1029/ 2002JD002247.

Guillevic, P.C., Bork-Unkelbach, A., Gottsche, F.M., Hulley, G., Gastellu-Etchegorry, J.P., Olesen, F.S., et al. (2013). Directional viewing effects on satellite land surface temperature products over sparse vegetation canopies-A multisensor analysis. IEEE Geoscience and Remote Sensing Letters, 10, 1464-1468. http://dx.doi.org/10.1109/LGRS.2013.2260319.

Hosgood, B., Jacquemoud, S., Andreoli, G., Verdebout, J., Pedrini, G., \& Schmuck, G. (1995) Leaf Optical Properties EXperiment 93 (LOPEX93).

Hsieh, C., Katul, G., \& Chi, T. (2000). An approximate analytical model for footprint estimation of scalar fluxes in thermally stratified atmospheric flows. Advances in Water Resources, 23, 765-772. http://dx.doi.org/10.1016/S0309-1708(99)00042-1.

Jacquemoud, S., \& Baret, F. (1990). PROSPECT: A model of leaf optical properties spectra. Remote Sensing of Environment, 34, 75-91. http://dx.doi.org/10.1016/0034-4257(90) 90100-Z.

Jupp, D.L.B., \& Strahler, A.H. (1991). A hotspot model for leaf canopies. Remote Sensing of Environment, 38, 193-210. http://dx.doi.org/10.1016/0034-4257(91)90089-0.

Kimes, D.S. (1983). Remote sensing of row crop structure and component temperatures using directional radiometric temperatures and inversion techniques. Remote Sensing of Environment, 13, 33-55. http://dx.doi.org/10.1016/0034-4257(83)90026-3.

Kimes, D.S., \& Kirchner, J.A. (1983). Directional radiometric measurements of row-crop temperatures. International Journal of Remote Sensing, 4, 299-311. http://dx.doi.org/ 10.1080/01431168308948548.

Lagouarde, J.P., Ballans, H., Moreau, P., Guyon, D., \& Coraboeuf, D. (2000). Experimental study of brightness surface temperature angular variations of maritime pine (Pinus pinaster) stands. Remote Sensing of Environment, 72, 17-34. http://dx.doi.org/10. 1016/S0034-4257(99)00085-1.

Lagouarde, J.P., Bach, M., Sobrino, J. A., Boulet, G., Briottet, X., Cherchali, S., et al. (2013a) The MISTIGRI thermal infrared project: scientific objectives and mission specifications. International Journal of Remote Sensing, 34(9-10), 3437-3466. http://dx.doi. org/10.1080/01431161.2012.716921.

Lagouarde, J.P., Commandoire, D., Irvine, M., \& Garrigou, D. (2013b). Atmospheric boundarylayer turbulence induced surface temperature fluctuations. Implications for TIR remote sensing measurements. Remote Sensing of Environment, 138, 189-198. http://dx.doi.org/ 10.1016/j.rse.2013.06.011

Lagouarde, J.P., Dayau, S., Moreau, P., \& Guyon, D. (2014). Directional Anisotropy of Brightness Surface Temperature Over Vineyards: Case Study Over the Medoc Region (SW France). IEEE Geosci. Remote Sens. Lett., 11, 574-578. http://dx.doi.org/10.1109/LGRS 2013.2282492.

Lagouarde, J.P., Hénon, A., Irvine, M., Voogt, J., Pigeon, G., Moreau, P., et al. (2012). Experimental characterization and modelling of the nighttime directional anisotropy of thermal infrared measurements over an urban area: Case study of Toulouse (France). Remote Sensing of Environment, 117, 19-33. http://dx.doi.org/10.1016/j.rse. 2011.06.022.

Lagouarde, J.P., Kerr, Y.H., \& Brunet, Y. (1995). An experimental study of angular effects on surface temperature for various plant canopies and bare soils. Agricultural and Forest Meteorology, 77, 167-190. http://dx.doi.org/10.1016/0168-1923(95)02260-5.

Lee, J., et al. (2013). Forest productivity and water stress in Amazonia: Observations from GOSAT chlorophyll fluorescence. Proceedings of the Biological Sciences, 280, 20130171 http://dx.doi.org/10.1098/rspb.2013.0171.

Leuning, R. (2002). Temperature dependence of two parameters in a photosynthesis model. Plant, Cell and Environment, 25, 1205-1210. http://dx.doi.org/10.1046/j. 1365-3040.2002.00898.x

Leuning, R., Kelliher, F.M., de Pury, D.G.G., \& Schulze, E.D. (1995). Leaf nitrogen, photosynthesis, conductance and transpiration: Scaling from leaves to canopies. Plant, Cell and Environment, 18, 1183-1200.

Lloyd, J., \& Farquhar, G.D. (1994). ${ }^{13} \mathrm{C}$ discrimination during $\mathrm{CO}_{2}$ assimilation by the terrestrial biosphere. Oecologia, 99, 201-215. http://dx.doi.org/10.1007/BF00627732.

Luquet, D., Bégué, a, Vidal, a, Clouvel, P., Dauzat, J., Olioso, a, et al. (2003). Using multidirectional thermography to characterize water status of cotton. Remote Sensing of Environment, 84, 411-421. http://dx.doi.org/10.1016/S0034-4257(02)00131-1.

Luquet, D., Vidal, a., Dauzat, J., Bégué, a., Olioso, a., \& Clouvel, P. (2004). Using directional TIR measurements and 3D simulations to assess the limitations and opportunities of water stress indices. Remote Sensing of Environment, 90, 53-62. http://dx.doi.org/10. 1016/j.rse.2003.09.008.

Medlyn, B.E., et al. (2002). Temperature response of parameters of a biochemically based model of photosynthesis. II. A review of experimental data. Plant, Cell and Environment, 25, 1167-1179. http://dx.doi.org/10.1046/j.1365-3040.2002. 00891.x.

Nelder, J.A., \& Mead, R. (1965). A Simplex Method for Function Minimization. Comput. J., 7 308-313. http://dx.doi.org/10.1093/comjnl/7.4.308.

Nielsen, D.C., Clawson, K.L., \& Blad, B.L. (1984). Effect of solar azimuth and infrared thermometer view direction on measured soybean canopy temperature. Agronomy Journal, 76, 607-610.

Norman, J.M. (1979). Modelling the complete crop canopy. In BJ Barfield, \& JF Gerber (Eds.), In Modification of the Aerial Environment of Crops. Am. Soc. Agric. Eng. Monogr, No. 2. (pp. 249-277). St Joseph, MI: ASAE.

Ogée, J., Brunet, Y., \& Loustau, D. (2003). MuSICA, a $\mathrm{CO}_{2}$, water and energy multilayer, multileaf pine forest model: Evaluation from hourly to yearly time scales and sensitivity analysis. Global Change Biology, 33, 697-717.

Olioso, A. (1992). Simulation des échanges d'énergie et de masse d'un couvert végétal, dans le but de relier la transpiration et la photosynthèse aux mesures de réflectance et de température de surface.

Olioso, A. (1995). Estimating the difference between brightness and surface temperatures for a vegetal canopy. Agricultural and Forest Meteorology, 1923, 237-242.

Olioso, A.H., Chauki, J.-., Wigneron, K., Bergaoui, P., Bertuzzi, A., Chanzy, P., et al. (1999). Estimation of energy fluxes from thermal infrared, spectral reflectances, microwave data and SVAT modeling. Phys. Chem. Earth, Part B Hydrol. Ocean. Atmos, 24 829-836. http://dx.doi.org/10.1016/S1464-1909(99)00089-1.

Paw, U.K., Ustin, S., \& Zhang, C. (1989). Anisotropy of thermal infrared exitance in sunflower canopies. Agricultural and Forest Meteorology, 95616 
Pinheiro, A.C.T., Privette, J.L., Mahoney, R., \& Tucker, C.J. (2004). Directional effects in a daily AVHRR land surface temperature dataset over Africa. IEEE Transactions on Geoscience and Remote Sensing, 42, 1941-1954. http://dx.doi.org/10.1109/TGRS. 2004.831886.

Porté, A., \& Loustau, D. (1998). Variability of the photosynthetic characteristics of mature needles within the crown of a 25-year-old Pinus pinaster. Tree Physiology, 18, 223-232.

Rasmussen, M.O., Gottsche, F. -M., Olesen, F. -S., \& Sandholt, I. (2011). Directional effects on land surface temperature estimation from Meteosat second generation for savanna landscapes. IEEE Transactions on Geoscience and Remote Sensing, 49, 4458-4468. http://dx.doi.org/10.1109/TGRS.2011.2144604.

Schymanski, S.J., Roderick, M.L., Sivapalan, M., Hutley, L.B., \& Beringer, J. (2008). A canopyscale test of the optimal water-use hypothesis. Plant, Cell and Environment, 31, 97-111. http://dx.doi.org/10.1111/j.1365-3040.2007.01740.x.

Snyder, W.C., \& Wan, Z. (1998). BRDF models to predict spectral reflectance and emissivity in the thermal infrared. IEEE Transactions on Geoscience and Remote Sensing, 36 , 214-225. http://dx.doi.org/10.1109/36.655331.

Thomas, D.S., Eamus, D., \& Bell, D. (1999a). Optimization theory of stomatal behaviour: I. A critical evaluation of five methods of calculation. Journal of Experimental Botany, 50 385-392. http://dx.doi.org/10.1093/jxb/50.332.385.

Thomas, D.S., Eamus, D., \& Bell, D. (1999b). Optimization theory of stomatal behaviour: Il. Stomatal responses of several tree species of north Australia to changes in light, soil and atmospheric water content and temperature. Journal of Experimental Botany, 50, 393-400. http://dx.doi.org/10.1093/jxb/50.332.393.

Timmermans, J., Van der Tol, C., Verhoef, a., Verhoef, W., Su, Z., van Helvoirt, M., et al. (2011). Quantifying the uncertainty in estimates of surface-atmosphere fluxes through joint evaluation of the SEBS and SCOPE models. Hydrology and Earth System Sciences Discussions, 8, 2861-2893. http://dx.doi.org/10.5194/hessd-8-2861-2011.

Timmermans, J., Verhoef, W., Van der Tol, C., \& Su, Z. (2009). Retrieval of canopy component temperatures through Bayesian inversion of directional thermal measurements.
Hydrology and Earth System Sciences Discussions, 6, 3007-3040. http://dx.doi.org/10. 5194/hessd-6-3007-2009.

Van de Griend, A., \& O'Neill, P.E. (1986). Discrimination of soil hydraulic properties by combined thermal infrared and microwave remote sensing. IGARSS'86 Symposium.

Van der Tol, C., Dolman, a. J., Waterloo, M.J., \& Raspor, K. (2007). Topography induced spatial variations in diurnal cycles of assimilation and latent heat of Mediterranean forest. Biogeosciences, 4, 137-154. http://dx.doi.org/10.5194/bg-4-137-2007.

Van der Tol, C. Verhoef, W. Timmermans, J., Verhoef, A, \& Su, Z (2009). An integrated model of soil-canopy spectral radiances, photosynthesis, fluorescence, temperature and energy balance. Biogeosciences, 6, 3109-3129. http://dx.doi.org/10.5194/bg-63109-2009.

Verhoef, W., Jia, L., Xiao, Q., \& Su, Z. (2007). Unified optical-thermal four-stream radiative transfer theory for homogeneous vegetation canopies. IEEE Transactions on Geoscience and Remote Sensing, 45, 1808-1822. http://dx.doi.org/10.1109/TGRS.2007.895844.

Voogt, J.A., \& Oke, T.R. (1998). Effects of urban surface geometry on remotely-sensed surface temperature. International Journal of Remote Sensing, 19, 895-920. http://dx. doi.org/10.1080/014311698215784.

Wallace, J., \& Verhoef, A. (2000). Modelling interactions in mixed-plant communities: Light, water and carbon dioxide. Leaf Development and Canopy Growth, 204-250.

Weis, E., \& Berry, J.A. (1988). Plants and high temperature stress. Symposia of the Society for Experimental Biology, 42, 329-346.

Wilson, K.B. Baldocchi, D.D. \& Hanson, PJ. (2000). Spatial and seasonal variability of photosynthetic parameters and their relationship to leaf nitrogen in a deciduous forest. Tree Physiology, 20, 565-578. http://dx.doi.org/10.1093/treephys/20.9.565.

Xu, L., \& Baldocchi, D.D. (2003). Seasonal trends in photosynthetic parameters and stomatal conductance of blue oak (Quercus douglasii) under prolonged summer drought and high temperature. Tree Physiology, 23, 865-877. http://dx.doi.org/ 10.1093/treephys/23.13.865. 